\title{
Effects of Intraparticle Heat and Mass Transfer During Devolatilization of a Single Coal Particle
}

\begin{abstract}
The objective of the present work is to elucidate the influence of intraparticle mass and heat transfer phenomena on the overall rate and product yields during devolatilization of a single coal particle in an inert atmosphere. To this end a mathematical model has been formulated which covers transient devolatilization kinetics and intraparticle mass and heat transport. Secondary deposition reactions of tarry volatiles also are included. These specific features of the model allow a quantitative assessment to be made of the impact of major process conditions such as the coal particle size, the ambient pressure and the heating rate on the tar, gas and total volatile yield during devolatilization. Model predictions are compared to a limited number of experimental results, both from the present work and from various literature sources.
\end{abstract}

\author{
ALFRED BLIEK, \\ W. M. van POELJE, \\ W. P. M. van SWAAIJ, \\ and F. P. H. van \\ BECKUM \\ Department of Chemical Engineering \\ Twente University of Technology \\ Enschede, The Netherlands
}

\begin{abstract}
SCOPE
Coal devolatilization is an important step in thermal coal conversion systems such as combustion, gasification, hydropyrolysis, and coke manufacturing. When coal is exposed to sufficiently high temperatures it decomposes into a complex mixture of gaseous and tarry components, leaving behind a solid residue. This process is accompanied by a significant weight loss. The volatiles of high molecular weight especially may represent either an important product or a serious burden. Consequently the devolatilization behavior of coal may have a far-reaching impact on the operation and performance of a wide range of coal conversion processes.

Many efforts have been made to obtain a better understanding of coal devolatilization and to develop mathematical models as engineering tools for process design and control. Early modeling concepts were almost entirely based on simple kinetic devolatilization schemes, sometimes in combination with intraparticle heat transfer models. Intraparticle mass transfer phenomena were either neglected altogether or were lumped into the kinetic equations. These pseudokinetic models are highly empirical. Widely varying kinetic constants have been reported, limiting the validity of these models to a narrow range of conditions. More serious, they fail to explain essential features of the devolatilization process. This is especially so where the influence of physical process parameters is concerned. It has long been recognized that factors like ambient pressure, heating rate, and coal particle size may significantly influence the overall kinetics as well as the product distribution during devolatilization.

Only fairly recently the need for a more rigorous treatment was appreciated and more comprehensive models were presented. One aspect, now generally recognized to be important,

Correspondence concerning this paper should be addressed to W. P. M. van Swaaij

is the influence of intraparticle tar deposition reactions on the ultimate weight loss and tar yield. Up to this time only few attempts have been made to account for the impact of tar deposition in a quantitative way. This is partly due to the fact that it is necessary to cope with the complex phenomenon of intraparticle mass transfer during coal devolatilization. In addition, very little is known about the nature and kinetics of tar deposition reactions within a coal particle. Nevertheless, two models of coal pyrolysis and coal hydropyrolysis in which tar deposition was explicitly accounted for have recently been presented. In both cases transients were ignored and the treatment was limited to isothermal conditions.

In the present work, the scope is extended to the treatment of coal devolatilization as a nonisothermal, transient process. We believe such an approach to be relevant for most practical conditions. In addition it will be shown that the mere existence of intraparticle temperature gradients may strongly influence the devolatilization process and the intraparticle tar deposition. In order to extend the applicability of the model to both low and high volatile efflux rates, the mass flux equations should account for the combined transport of volatiles by viscous flow and diffusion. For this reason the mass flux equations are derived from the continuum limit of the so-called "Dusty Gas" model.

The relevance of the present model is that it allows a quantitative assessment of the conversion-time behavior, as well as the ultimate yields of tar and gas, over a wide range of process conditions. Experimental observations indicate that variations in the ultimate yield of tarry and gaseous volatiles can be expected when factors such as coal particle size, heating rate, and ambient pressure are changed. It will be shown to what extent secondary deposition reactions can be held responsible for these variations. Hence, the model presented may contribute to the development of a more unifying theory of coal devolatilization.
\end{abstract}




\section{CONCLUSIONS AND SIGNIFICANCE}

Historically, the complicated interaction between the chemical kinetics and the physical transport phenomena during coal devolatilization has seriously impeded the interpretation of experimental results. The influence of factors such as coal particle size, ambient pressure, and heating rate has been well established experimentally, but the mechanism underlying the observed behavior has remained obscure. It is often postulated that the observed yield variations for tarry and gaseous products can be attributed to secondary deposition reactions. In the present model such deposition reactions have explicitly been included.

The present model describes the nonisothermal process of devolatilization of a single coal particle. The coal volatiles are treated as a binary mixture of gaseous and tarry species. Consequently, the present model is not used to predict the evolution rate of individual volatile species. The intraparticle mass transport equations, derived from the Dusty Gas model, account for the combined action of composition and pressure gradients. Therefore the model can be applied to a very broad particle size range. The coal particle is treated as a porous solid which essentially retains its original structure in the course of devolatilization. Therefore, the predictive capabilities of the model may be limited to noncaking coals. The characteristic melting phenomena observed for caking coals have led to the development of highly specific bubble nucleation models. Indeed, results of the present model are in part at variance with experimental findings for caking coals. For lignites a fair agreement with available experimental observations is obtained.

Model predictions are given for a wide range of pyrolysis conditions. These predictions are presented in the form of the conversion-time behavior and the ultimate tar and total volatile yield. In addition, the intraparticle profiles of pressure, temperature, and composition have been obtained. It is shown that for small and intermediate particle sizes, the extent of tar deposition is largely governed by the resistance to mass transfer. This resistance is reflected by the mean intraparticle tar concentration, which is controlled by diffusion for small particles and by viscous flow for intermediate and large particle sizes. This means that the tar yield increases when the mass transfer resistance is reduced.
With an increasing heating rate the intraparticle residence time of coal volatiles is reduced. Consequently one would expect the degree of tar deposition to be less. Surprisingly, this reasoning holds only until a critical heating rate is reached. Beyond this value the degree of tar deposition increases again. The explanation for this behavior is that under severely heat transfer controlled conditions the pyrolysis reaction proceeds by an unreacted shrinking core mechanism. In this case the coal volatiles, generated at the inner core of the particle, are released only after the outer layer of the particle has reached a high temperature. Hence a substantial part of these tarry volatiles are cracked in the outer region of the particle. Consequently, the tar yield passes through a maximum as a function of the particle heating rate. In contrast to what is generally assumed, the effect of the particle heating rate is therefore not necessarily unidirectional. To our knowledge this result has not been demonstrated before.

On account of the various counteracting phenomena involved, the ultimate volatile yield increases only marginally, if at all, when high heating rates are applied. This result is at variance with some experimental findings. It is frequently reported that the ultimate yield of volatiles may increase as much as 10 to $30 \%$ at flash heating conditions. Anthony and Howard (1976) suggested that this may be attributed to intraparticle tar deposition reactions. These authors argue that at high heating rates the intraparticle residence time is reduced, resulting in a lower degree of tar deposition and a higher volatile yield. In our opinion the results of the present model clearly show that this reasoning may not be valid. Consequently, we tend to favor the explanation for the heating rate effect offered by Kobayashi (1976). This author suggested that coal devolatilization may follow a different route at high heating rates because competitive reactions are involved. This may indeed offer a plausible explanation for the experimental findings. As pointed out by Reidelbach (1979), this is not necessarily in conflict with the experimental observations of Anthony and Howard, who noticed no yield increase when applying heating rates between 750 and $10,000^{\circ} \mathrm{C} / \mathrm{s}$, as the shift in reaction path may have occurred already at lower heating rates.

\section{INTRODUCTION}

When coal is exposed to high temperatures, devolatilization takes place. During this thermal decomposition process a complex mixture of water vapor and gaseous and tarry components evolves. A solid residue, the char, remains. In the course of reaction the coal structure may change considerably due to swelling or mesophase formation.

Devolatilization is an important step in thermal coal conversion processes because a significant part of the mass and chemical energy of the coal is involved. Moreover, the evolution of high molecular weight products has to be taken into consideration. Depending on the objective of the conversion process, the condensable heavy products--tars--can be either a valuable or a highly undesirable product. Consequently, mathematical modeling of coal devolatilization has been, and still is, a prominent subject. As an introduction to the presentation of our model, some existing models will be discussed.

In most coal devolatilization models formal kinetics are used and it is usually assumed that the rate of devolatilization is proportional to the amount of volatiles yet to be released:

$$
\begin{gathered}
C \rightarrow V+S \\
\frac{d V}{d t}=k_{o} \cdot \exp (-E / R T) \cdot\left(V_{\infty}-V_{t}\right)
\end{gathered}
$$

Various kinetic schemes involving single or multiple reaction steps have been proposed. In their review article, Anthony and Howard (1976) presented a lengthy discussion of the various aspects of these reaction schemes. They clearly demonstrated that single, unidirectional reaction schemes, as above, suffer from a number of disadvantages. The most serious drawback is probably the need to treat the ultimate volatile yield $V_{\infty}$ as a variable quantity, rather than as a constant, in order to explain experimental results.

An overwhelming number of experimental observations indicate that the ultimate yield of volatile matter is a function of the pyrolysis conditions, such as the ambient pressure, the heating rate, and the coal particle size. The experimental observations have 
brought up the subject of secondary deposition reactions of tarry matter within the devolatilizing coal particle. Clearly these reactions must be treated in conjunction with the presence of intraparticle mass transfer resistances. Anthony and Howard (1976) recognized the possible role of secondary reactions and they introduced a competition parameter between diffusional escape and recombination reactions of volatile components. The use of such a parameter is an oversimplification of the problem. James and Mills (1976) showed that at high heating rates, as applied by Anthony, the predominant mass transport mechanism is not diffusion but viscous flow, due to the large net during coal pyrolysis. The fact that Anthony and Howard succeeded quite well in covering their experimental observations may therefore be fortuitous.

Different devolatilization models have been presented by Lewellen (1975) and Attar (1978), and more recently by $\mathrm{Oh}$ (1983). Because bituminous coals exhibit a strong influence of ambient pressure on the ultimate coal conversion, these authors have explicitly accounted for intraparticle deposition reactions. The mathematical models presented by Attar and Lewellen are based upon the nucleation and growth of bubbles of volatile matter, which are transported through a viscous melt. These phenomena can be considered typical for caking, bituminous coals. In contrast, the present model presumes that the coal particle retains a rigid structure in the course of devolatilization.

Russel et al. (1979) have presented a rigorous treatment of intraparticle mass transfer effects during hydrogasification of coals. They employed the Dusty Gas model (Mason and Evans, 1967) to cope with the simultaneous mass transfer by diffusion and viscous flow. The flux equations were solved for a ternary mixture, consisting of reactive and nonreactive volatiles, as well as hydrogen. The binary diffusion coefficients for this mixture were assumed to be equal. This is disputable in view of the large molecular weight difference between coal volatiles and hydrogen. In a later treatment by Ward and Russel (1981) it was shown that indeed the quantitative solutions of the model may be affected by this assumption. Russel et al. (1979) treated the pressure and mole fraction gradients as pseudostationary quantities and only considered the case of isothermal particles. These factors reduce the applicability of the model to small, instantaneously heated coal particles.

A more or less similar model was presented by Gavalas and Wilks (1980) for the devolatilization of coal in an inert atmosphere. In contrast to Russel et al., these authors did not apply the continuum limit of the Dusty Gas model, but they also accounted for Knudsen diffusion. The flux equations were solved for a ternary mixture of gas, tar, and an inert component. An interesting feature of the model of Gavalas and Wilks is the explicit incorporation of the details of the solid structure, such as the pore size distribution and the pore interconnectivity. This may be a valuable new approach. However, by treating the net tar and gas formation rates as known quantities the inherently transient nature of the devolatilization process is lost and the applicability is reduced to isothermal conditions. The treatment of the net tar formation rate as a known quantity may even be untenable. This is obvious when one realizes that tar formation is influenced by intraparticle deposition reactions. These in turn are governed by the local tar concentrations. Hence the model of Gavalas and Wilks can merely be applied to derive some qualitative conclusions. Some of these conclusions have been used in the present work.

A more realistic approach was taken by Tsang (1980). He modeled heat and mass transfer during the drying and pyrolysis of large coal blocks. Tsang describes the evolution of individual volatile components under nonisothermal conditions. Mass transfer was assumed to be dominated by viscous flow, which simplifies the mathematics considerably. This approach is justified for large coal particles. Unfortunately, Tsang ignored secondary deposition reactions because of the absence of sufficient reliable data. In the present work the intraparticle mass transfer equations also are derived from the Dusty Gas model. However, in our case the transient nature of coal devolatilization is retained and both the mass flux equations and the kinetics are treated accordingly. Instead of analyzing the characteristic time scales (Russel et al.) or taking the rates of formation of volatiles as known quantities (Gavalas and Wilks), conventional kinetic equations are used in our model to describe devolatilization and deposition reactions. A final difference between the present work and that of the above-mentioned authors is that in our analysis nonisothermal coal devolatilization is covered. This is done because we feel that in most conditions where mass transfer resistances are important, instantaneous heat-up is only possible when the final temperatures are comparatively low.

\section{THE KINETIC SCHEME OF DEVOLATILIZATION}

Chemically speaking, caal devolatilization is the thermal degradation of the coal structure by a complicated set of bond-breaking and ring-opening reactions. These are followed by interradical reactions of volatile fragments. Various attempts have been made to consider the process from a fundamental point of view by accounting for the reactivity of specific organic groups present in coal Cheong (1977) has employed such an approach.

The inherent complexity of such models renders them unsuitable for engineering purposes. For reactor design applications it is common practice to follow simply the mass evolution rate of either single or all volatile species. The kinetic scheme is usually simplified by assuming unidirectional decomposition reactions, according to Eq. 1. The solid conversion rate can thus be expressed as the lumped production rate of all volatile species.

A somewhat different concept was introduced by Anthony and Howard (1976), following previous work of Vand (1943) and Pitt (1962). These authors assumed the devolatilization to proceed by numerous independent, parallel reactions with a Gaussian distributed activation energy, see Eqs. 2a-c.

$$
\begin{gathered}
\frac{d V_{i}}{d t}=k_{o} \cdot \exp \left(-E_{i} / R T\right) \cdot\left(V_{\infty, i}-V_{t, i}\right) \\
d V_{i}=V_{\infty} \cdot f(E) \cdot d(E) \\
f(E)=\frac{1}{\sigma \sqrt{2 \pi}} \cdot \exp \left\{\frac{-\left(E-E_{o}\right)^{2}}{2 \sigma^{2}}\right\}
\end{gathered}
$$

In the model of Anthony the single activation energy $E$ is replaced by a mean activation energy $E_{o}$ and a standard deviation $\sigma$.

Whereas the models pointed out above are used to describe either the solid conversion or the generation of lumped volatile components, so-called product evolution models are used to describe the release of individual volatile components (Luther, 1968; Jüntgen and van Heek, 1968; Suuberg et al., 1977; Campbell, 1978; Weimer and Ngan, 1979; Solomon and Colket, 1978). Clearly this approach is more laborious as the kinetics of evolution have to be determined for a large number of components.

For the present work the main objective is to illustrate the effect of intraparticle deposition reactions. Therefore the tarry components have to be treated as a separate group of volatiles. In order to simplify the numerical treatment of mass transfer in the multicomponent mixture of volatiles, all other volatile species are lumped into the category "gas." The formation of tars and gases is taken to proceed by independent, unidirectional reactions. A slow secondary degassing step, producing gaseous components, is also incorporated. In order to reduce the number of kinetic parameters, we have opted to model each reaction path as a singte reaction. The experimentally observed "tailing" of the weight loss curves (see the section covering experimental results) can be accommodated by assuming each reaction to be second-order in the amount of 


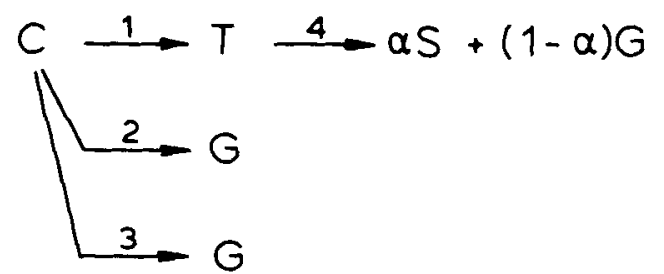

Figure 1. Kinetic scheme for coal devolatilization.

Devolatilization kinetics: $d v_{l} / d t=k_{0, t} \cdot \exp \left(-E_{l} / R T\right) \cdot\left(v_{t, \infty}-v_{l, t}\right)^{2}$

Tar Deposition kinetics: $d[t] / d t=-k_{0.4} \cdot \exp \left(-E_{4} / R T\right) \cdot[t]$

volatiles yet to be released. This approach is not uncommon and it should be realized that the rate equations merely represent formal, lumped kinetics describing the conversion-time behavior.

It is generally accepted that especially high boiling tar constituents and aromatic structures are liable to deposition reactions (Eddinger, 1966; Peters, 1960; Tyler, 1979; Gray, 1974; Pottgiesser, 1980). Probably both cracking and repolymerization reactions play a role. In the absence of accurate data, it has been assumed here that all tarry volatiles are involved in deposition reactions and that these reactions are first-order in the tar concentration. Furthermore, tar deposition is taken to be accompanied by the release of gaseous products, in accordance with results of Peters (1960), Pottgiesser (1980) and Arendt (1980).

The total kinetic scheme and rate equations used in the present model are given in Figure 1.

\section{INTRAPARTICLE MASS TRANSFER}

\section{Flux Equations}

Coal devolatilization is accompanied by the generation of a large volume of volatile components; consequently, intraparticle pressure gradients will develop. In addition, composition gradients exist because the formation kinetics of tarry and gaseous species are different and because the tar mole fraction at the gas-solid interphase is assumed to be zero in the present case. One of the simplest models, treating the problem of mass transfer under the combined action of pressure and composition gradients, is the Dusty Gas model (Mason and Evans, 1967; Mason and Malinauskas, 1983). Under the assumption that thermal diffusion as well as surface diffusion can be neglected, the general Dusty Gas flux equation is formulated as:

$$
\frac{N_{i}}{D_{k, i}^{e}}+\sum_{\substack{j=1 \\ j \neq i}}^{n} \frac{x_{j} N_{i}-x_{i} N_{j}}{D_{i, j}^{e}}=-\frac{P}{R T} \nabla x_{i}-\frac{x_{i}}{R T}\left\{1+\frac{B o P}{\mu_{m} \cdot D_{k, i}^{e}}\right\} \nabla P
$$

These flux equations are valid for any homoporous solid. As will be shown the next section, the contribution of Knudsen diffusion to macroscopic volatiles transport can be neglected. One may therefore take the continuum limit of the Dusty Gas model, obtained by setting $B o P / \mu_{m} \gg D_{k, i}^{e} \gg D_{i, j}^{e}$ for any $i, j$. For the continuum limit of the model $(n-1)$, equations of the type of Eq. 4 are independent

$$
\sum_{\substack{j=1 \\ j \neq i}}^{n} \frac{x_{j} N_{i}-x_{i} N_{j}}{D_{i, j}^{e}}=-\frac{P}{R T} \nabla x_{i}-\frac{x_{i}}{R T}\left\{1-\frac{1}{D_{k, i}^{e} \sum_{j=1}^{n}\left(\frac{x_{j}}{D_{k, j}^{e}}\right)}\right\} \nabla P
$$

$$
\sum_{j=1}^{n} \frac{N_{j}}{D_{k, j}^{e}}=-\frac{B o P}{\mu_{m} \cdot R T} \sum_{j=1}^{n}\left(\frac{x_{j}}{D_{k, j}^{e}}\right) \nabla P
$$

Equation 5, characterizing the total net flux, governs the development of the intraparticle pressure. In their treatment of hydropyrolysis of small coal particles, Russel et al. (1979) ignored Eq. 5 on the basis of their assumption that the intraparticle pressure build-up is small. As will be shown later, this assumption is not realistic for devolatilization of medium and large particles. Hence, Eq. 5 must be solved.

The flux equations are applied to a mixture of volatile components. In the present case only two volatiles are distinguished, tar and gas. In addition, an inert carrier gas is normally present in devolatilization experiments. Gavalas and Wilks (1980) have solved the Dusty Gas equations for such a ternary mixture. These authors concluded that the presence of inert components does not influence the devolatilization process to any significant extent, because these are rapidly driven out of the coal particle. Therefore the flux equations will be solved for a binary mixture. This allows them to be expressed in their explicit form:

$$
\begin{gathered}
N_{t}=-\frac{P}{R T} \frac{D_{g, t}^{e}}{\left\{1+(\sqrt{m}-1) x_{t}\right\}} \nabla x_{t}-\frac{x_{t} B o P}{\mu_{m} R T} \nabla P \\
\frac{N_{g}}{\sqrt{m}}+N_{t}=-\left\{x_{t}+\frac{\left(1-x_{t}\right)}{\sqrt{m}}\right\} \frac{B o P}{\mu_{m} R T} \nabla P
\end{gathered}
$$

with

$$
m=\frac{M_{t}}{M_{g}}\left(=\left(\frac{D_{k, g}}{D_{k, t}}\right)^{2}\right)
$$

\section{Mass Transport Parameters and Solid Structure}

In the general Dusty Gas flux equations the structural properties of the solid that are relevant to intraparticle flow are the viscous permeability $B o$, the effective Knudsen diffusivity $D_{k, i}^{e}$ and the effective binary diffusivity $D_{i, j}^{e}$. These parameters are defined in subsequent order by Eqs. 5, 8, and 9 .

$$
\begin{gathered}
D_{k, i}^{e}=k_{1} \cdot\left\{\frac{8 R T}{\pi M_{i}^{*}}\right\}^{1 / 2} \quad\left(\mathrm{~m}^{2} \mathrm{~s}^{-1}\right) \\
D_{i, j}^{e}=k_{o} \cdot D_{i, j} \quad\left(\mathrm{~m}^{2} \mathrm{~s}^{-1}\right)
\end{gathered}
$$

The magnitudes of the permeability factors $B o, k_{1}$, and $k_{o}$ are uniquely determined by the structural properties of the solid considered. For solids with a narrow pore size distribution and a well interlinked pore system, $B o$ and $k_{1}$ can be obtained by assuming a single, mean pore size $\bar{d}_{p o}$ (Roy, 1974; Russel et al., 1979).

$$
\begin{gathered}
\text { Bo }=\frac{\bar{d}_{p o}^{2}}{32} \quad\left(\mathrm{~m}^{2}\right) \\
k_{1}=1 / 3 \bar{d}_{p o} \quad(\mathrm{~m})
\end{gathered}
$$

However, coals and coal-derived chars are known to have a broad pore size distribution, ranging from micropores to microcracks (Gan, 1972). The physical meaning of the mean pore size may therefore be absent and the use of this parameter is likely to produce erroneous results (Wen and $\mathrm{Wu}, 1976$ ).

The relevance of the question of pore interconnectivity in coal chars was recognized and discussed by Gavalas and Wilks (1980). These authors concluded that for devolatilization of a $100 \mu \mathrm{m}$ particle, the mesopores of about $1 \mu \mathrm{m}$ act as the main source of volatiles. This means that the micropore system is either not directly connected to the particle surface or that these pores are largely bypassed when macroscopic transport is considered. Interestingly, a similar conclusion was reached by Simons and Finson (1979). This result implies that the char structure can be visualized as in Figure 2. 


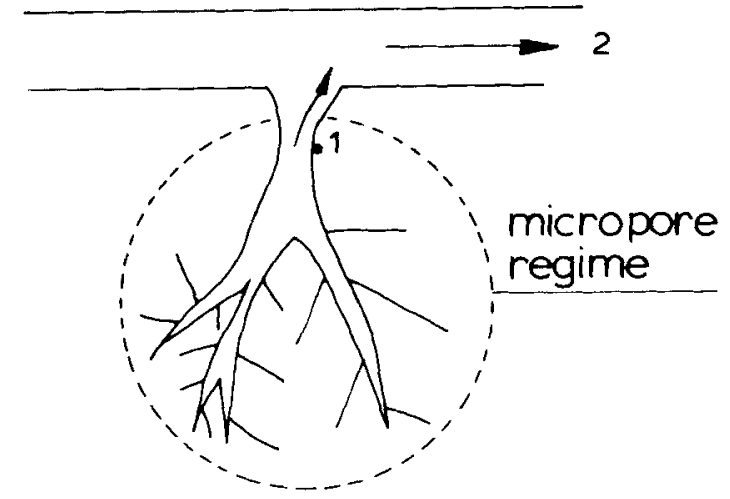

Figure 2. Schematic representation of mass transport during coal devolatilization.

1. Volatiles formation and slow release of volatiles into the macropore system

2. Macroscopic transport of coal volatiles and secondary deposition reactions of tar.

Macroscopic transport of coal volatiles thus occurs predominantly through larger pores. The results of Gavalas and Wilks (1980) suggest that these carrier pores are larger than $1 \mu \mathrm{m}$ when the coal particle size exceeds $100 \mu \mathrm{m}$. For a pore size of $1 \mu \mathrm{m}, B o$ and $k_{1}$ can be obtained from Eqs. 10 and 11 . The binary diffusion coefficient follows from the Chapman-Enskog equation (Reid et al., 1967):

$$
D_{g, t}=1.86 \times 10^{-22} \frac{T^{1.5}}{P \sigma_{g, t}^{2} \Omega_{D}}\left\{\frac{1}{M_{t}}+\frac{1}{M_{g}}\right\}^{0.5} \quad\left(\mathrm{~m}^{2} \mathrm{~s}^{-1}\right\rangle
$$

Taking $P=10^{5} \mathrm{~Pa}, T=500^{\circ} \mathrm{C}$ and further physical properties of tar and gas as in Table 3 , it is easily shown that for pores larger than $1 \mu \mathrm{m}$ in diameter $B o \cdot P>\mu \mathrm{m} \cdot D_{k, t}$ and $D_{k, t}>D_{g, t}$. Macroscopic volatiles transport is thus governed by viscous flow and binary diffusion, and the Dusty Gas model may be simplified to its continuum limit.

For the present work the magnitude of $B o$ and $k_{o}$ are obtained from experimental observations. Because only macroscopic transport is considered here, both factors should be obtained from stationary mass flux experiments. The results of such experiments from various literature sources are given in Figures 3 and 4. In both cases $B o$ and $k_{o}$ have been plotted against the total particle porosity. Clearly, the details of the pore structure are lost in this way. Nevertheless, this procedure can be justified as the main governing factors, the pore tortuosity and the probability of pore space continuity, are related to the particle porosity (Wakao and Smith, 1964; Millington and Quirk, 1961). On the analogy of the Kozeny-Carman equation, derived for the viscous permeability of a bed of unconsolidated spheres under laminar flow conditions (Carman, 1956), Bo can be expressed as

$$
B o=\frac{\theta_{p}^{3}}{S_{p}^{2}}
$$

For moderate mass conversion levels the internal surface area $S_{p}$ can be expressed as a function of the particle porosity $\theta_{p}$, on the basis of the pore model of Bhatia and Perlmutter (1981):

$$
\begin{aligned}
& S_{p} \propto\left(1-\theta_{p}\right) \\
& B o \propto \frac{\theta_{p}^{3}}{\left(1-\theta_{p}\right)^{2}}
\end{aligned}
$$

When Eqs. 14 and 13 are combined, Eq. 15 is obtained, which provides a reasonable fit of the experimental data (Figure 3 ). The proportionality constant in $\mathrm{Eq} .15$ was experimentally determined for the coals presently investigated. Somewhat lower values than indicated in Figure 3 had to be used, (Table 3).

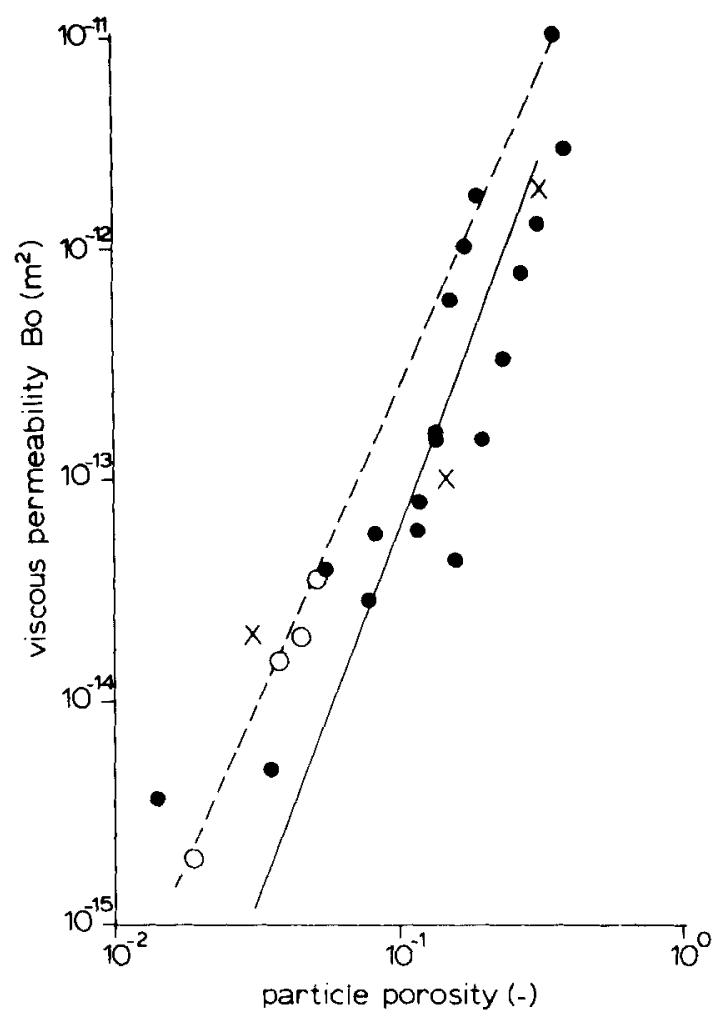

Figure 3. Viscous permeability of solid coal and char samples vs. particle porosity.

O Dabbous (1974)

$\times$ Lien (1977)

- Reznik (1978)

The original data of Reznik are given as the $B o$ vs. coal water saturation. These are recalculated according to $\theta=\theta_{0}(1-\beta)$. $\left[\sigma_{0}\right.$, dry sample porosity; $\beta$, water saturation tactor.]

$--B O=1.5 \times 10^{-10} \cdot \theta^{2.8}\left(\mathrm{~m}^{2}\right)$, Tsang (1980)

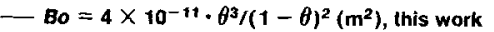

Experimentally obtained values for $k_{o}$, as presented in Figure 4, can be covered reasonably well with Eq. 16. Similar equations were used by Bhatia and Perlmutter (1981), Hashimoto and Silveston (1973), Arri (1978), and Wen and Wu (1976).

$$
k_{o}=0.4 \ell_{p}^{3}
$$

\section{CONSERVATION EQUATIONS FOR HEAT AND MASS}

The volatiles released from the coal are subdivided into tarry and gaseous species. Consequently two mass conservation equations and one heat conservation equation will have to be formulated. As will be shown later, rapidly changing profiles of pressure, composition, and temperature will develop within the particle. Therefore the conservation equations are formulated in their nonstationary form.

\section{Mass Conservation Equations}

$$
\begin{gathered}
\frac{\partial}{\partial t}\left\{\theta_{p} M_{g} x_{g} \frac{P}{R T}\right\}+\frac{1}{r^{2}} \frac{\partial}{\partial r}\left(r^{2} M_{g} N_{g}\right)=\frac{1}{\rho_{o}} \sum_{i} R_{g, i} \\
\frac{\partial}{\partial t}\left\{\theta_{p} M_{i}\left(1-x_{g}\right) \frac{P}{R T}\right\}+\frac{1}{r^{2}} \frac{\partial}{\partial r}\left(r^{2} M_{t} N_{t}\right)=\frac{1}{\rho_{o}} \sum_{i} R_{t, i}
\end{gathered}
$$




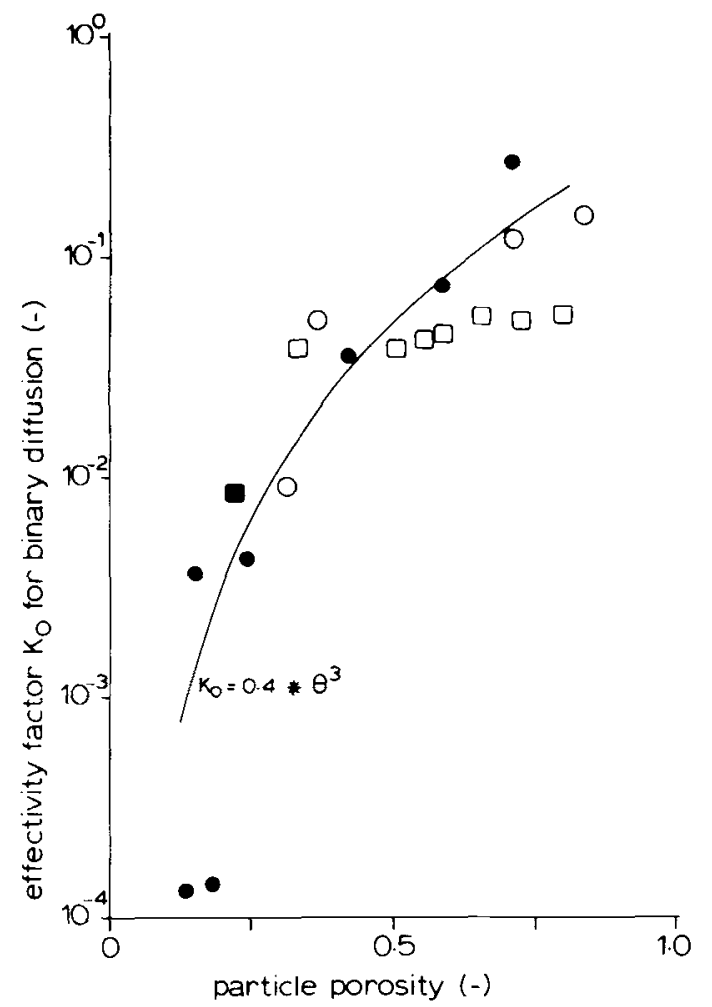

Figure 4. Effectivity factor for steady state binary diffusion through solid coal and char samples.

$\square$ Wen (1976)

Evans (1961)

O Turkdogan (1970)

- Bilek (1984)

In Eqs. 17 and $18 \sum_{i} R_{g, i}$ and $\sum_{i} R_{t, i}$ stand for the total net mass production rates of gaseous and tarry components, respectively. The molecular weights $M_{t}$ and $M_{g}$ are treated as being constant throughout the devolatilization process. In addition, the particle porosity changes are small compared to concentration variations. The intraparticle mass conservation equations are simplified to

$$
\begin{gathered}
\theta_{p} \frac{\partial}{\partial t}\left\{\frac{x_{g} P}{R T}\right\}+\frac{1}{r^{2}} \frac{\partial}{\partial r}\left(r^{2} N_{g}\right)=\frac{1}{M_{g} \rho_{o}} \sum_{i} R_{g, i} \\
\theta_{p} \frac{\partial}{\partial t}\left\{\frac{\left(1-x_{g}\right) P}{R T}\right\}+\frac{1}{r^{2}} \frac{\partial}{\partial r}\left(r^{2} N_{t}\right)=\frac{1}{M_{t} \rho_{o}} \sum_{i} R_{t, i}
\end{gathered}
$$

The appropriate boundary and initial conditions for the mass flux equations are formulated under the assumption that the mass transport from the particle outer boundary to the surrounding atmosphere is infinitely fast. Furthermore, the particle surrounding is assumed to consist of gaseous components. In the assumed binary system the initial and the ambient mole fraction of gaseous volatiles are therefore set equal to one.

$$
\begin{gathered}
t=0 ; 0 \leq r \leq R_{p}: P=P_{o}, x_{g}=1 \\
r=0 ; \quad: \nabla P=\nabla x_{g}=0 \\
r=R_{p} ; \quad: P=P_{a}, x_{g}=1
\end{gathered}
$$

The heat conservation equation is formulated under the assumption that the heat effect of devolatilization reactions is negligible. The effect of the heat of reaction during pyrolysis can be assessed by comparing the order of magnitude of this heat effect to the change

\begin{tabular}{lcc}
\hline & $\begin{array}{c}\text { German } \\
\text { Lignite }\end{array}$ & $\begin{array}{c}\text { Polish HVB } \\
\text { Bituminous }\end{array}$ \\
\hline Proximate Analysis & & \\
Moisture (a.r.) & $14 \%$ & $5 \%$ \\
V.M. (d.a.f.) & 51.8 & 35.7 \\
F.C. (d.a.f.) & 48.2 & 64.3 \\
Ash (a.r.) & 4.0 & 6.2 \\
Ultimate Analysis (\% d.a.f.) & & \\
Carbon & 66.9 & 81.8 \\
Oxygen & 25.7 & 11.6 \\
Nitrogen & 0.64 & 0.6 \\
Hydrogen & 7.2 & 5.1 \\
Sulfur & 0.5 & 0.45 \\
Chlorine & 0.03 & 0.14 \\
\hline
\end{tabular}

in the sensible enthalpy content of the coal, using the dimensionless ratio $\phi$ :

$$
\phi=\left[\frac{d V}{d T}\right]_{\text {maximum }} \cdot \Delta H_{r} / C_{p, s}
$$

The maximum pyrolysis rate calculated for Polish HVB coal at the highest heating rate investigated $\left(1,000 \mathrm{~K} \cdot \mathrm{s}^{-1}\right)$ is around $2 \times 10^{-3}$ $\mathrm{g} \cdot \mathrm{g}^{-1} \cdot \mathrm{K}^{-1}$. Taking the heat of reaction during pyrolysis to be 200 $\mathrm{J} \cdot \mathrm{g}^{-1}$ coal (Reidelbach, 1979) and taking $C_{p, s}=2 \mathrm{~J} \cdot \mathrm{g}^{-1} \mathrm{~K}^{-1}$ it is easily shown that the ratio $\phi$ is small, even for the extreme conditions mentioned above. Therefore the heat effect of pyrolysis can be neglected, and the heat conservation equation is formulated accordingly:

$$
\frac{\partial}{\partial t}\left\{\rho_{s} c_{p, s} T_{s}\right\}=\frac{1}{r^{2}} \frac{\partial}{\partial r}\left(r^{2} \lambda_{s}^{e} \frac{\partial T_{s}}{\partial r}\right)-\sum_{i=g, t} N_{i} M_{i} c_{p, i} \frac{\partial T}{\partial r}
$$

The heat transport from the surroundings to the outer surface of the particle is governed by the operating conditions of a pyrolysis reactor. It is bypassed here by assuming a constant surface heating rate until the final temperature $T_{f}$ is reached. The appropriate boundary and initial value conditions are thus formulated as:

$$
\begin{gathered}
t=0,0 \leq r \leq R_{p}: T_{s}=T_{o} \\
r=0 \quad: \nabla T=0 \\
r=R_{p}, T_{s}<T_{f}: T_{s}=T_{o}+m_{H} t \\
t \geqslant\left(T_{f}-T_{o}\right) / m_{H}: T_{s}\left(R_{p}\right)=T_{f}
\end{gathered}
$$

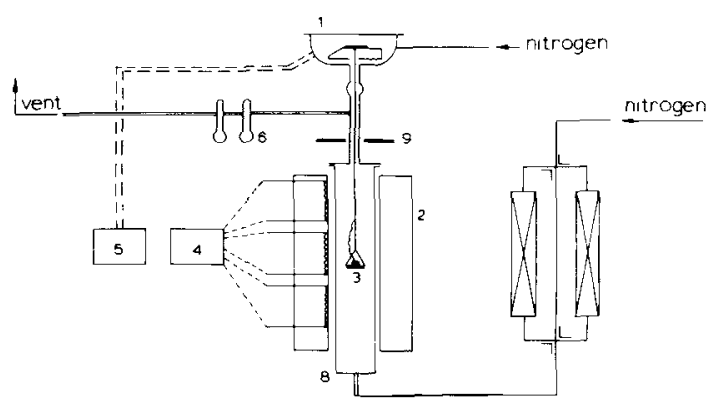

Figure 5. Large-sample TGA.

1. Mettler 400 continuous weighing unit and housing; 2 . Three-zone furnace; 3. Sample basket; 4. P.i.d. temperature controller; 5. Temperature recording; 6. Tar trap; 7. BASF R-3-11 oxygen removal catalyst; 8 . High-temperature steel furnace tube, $3^{\prime \prime} 1.0$; 9 . radlation shield. 
Table 2. Pyrolysis Kinetics and Structural Parameters of Coals investigated

\begin{tabular}{lcc}
\hline & $\begin{array}{c}\text { German } \\
\text { Lignite }\end{array}$ & $\begin{array}{c}\text { Polish HVB } \\
\text { Bituminous }\end{array}$ \\
\hline$K_{01}, \mathrm{~s}^{-1}$ & $7.6 \times 10^{11}$ & $1.65 \times 10^{12}$ \\
$K_{02}, \mathrm{~s}^{-1}$ & $8 \times 10^{4}$ & $8.36 \times 10^{3}$ \\
$K_{03}, \mathrm{~s}^{-1}$ & - & $3.68 \times 10^{6}$ \\
$E_{1}, \mathrm{~kJ} / \mathrm{mol}$ & 156 & 188 \\
$E_{2}, \mathrm{~kJ} / \mathrm{mol}$ & 93 & 72.2 \\
$E_{3}, \mathrm{~kJ} / \mathrm{mol}$ & - & 142.5 \\
$K_{04}, \mathrm{~s}^{-1}$ & $2.7 \times 10^{4}$ & $2.7 \times 10^{4}$ \\
$E_{4}, \mathrm{~kJ} / \mathrm{mol}$ & 60 & 60 \\
$v_{1, \infty}, \%$ d.a.f. & 16.0 & 16.9 \\
$v_{2, \infty}, \%$ d.a.f. & 35.8 & 9.0 \\
$v_{3, \infty}, \%$ d.a.f. & - & 6.5 \\
$\alpha$ & 0.8 & 0.8 \\
Coal porosity $\theta_{0}$ & 0.10 & 0.08 \\
Char porosity $\theta_{\infty}$ & 0.25 & 0.20 \\
Coal particle density, $\mathrm{kg} / \mathrm{m}^{3}$ & 900 & 1,270 \\
\hline
\end{tabular}

The thermal properties of the coal as well as the coal density and void fraction are treated as pseudostationary quantities, according to the equations listed in Table 3.

\section{MODEL PREDICTIONS AND EXPERIMENTAL RESULTS}

\section{Experimental Procedure}

In order to obtain kinetic devolatilization data for the two coals presently studied, German lignite and Polish HVB bituminous (Table 1), experiments were carried out in a Chan-2000 thermogravimetric analyzer. In this unit, (Bliek, 1984), weight loss data were measured for particle sizes of 50-1,000 $\mu \mathrm{m}$, at both atmospheric and subatmospheric pressure. The accuracy of the weight measurement is better than $0.02 \mathrm{mg}$.

Samples of 10-15 $\mathrm{mg}$ freshly crushed coal were placed in a quartz sample basket, inside the furnace hangdown tube; see Figure 5 . This tube was flushed with high-purity nitrogen until oxygen levels lower than $1 \mathrm{ppm}$ were obtained. Subsequently the coal sample was dried in situ at $110^{\circ} \mathrm{C}$ and the devolatilization was initialized by raising the furnace temperature at an accurately controlled, specified rate up to $950^{\circ} \mathrm{C}$. During this period both the sample weight and temperature were recorded continuously.

From the experimentally observed weight loss curves for $44-53 \mu \mathrm{m}$ coal particles the kinetic constants for the devolatilization scheme (Figure 1) were obtained by a fitting procedure. Because only the total weight loss was measured, the initial guess in the parameter estimation for the tar formation kinetics was obtained from literature sources. To this end data of Pottgiesser (1980) on Zollverein coal and of Suuberg et al. (1977) on Montana lignite were used for the Polish HVB coal and the German lignite respectively. The kinetic data were obtained by a least squares curve-fitting technique. The nonisothermal kinetics were treated according to the mathematical analysis presented by Jüntgen (1970). In case this procedure proved to be inaccurate, a continued fraction analysis (Khovanski, 1963) was utilized. The kinetic parameters obtained in this way are listed in Table 2. A nearly perfect fit is obtained with experimental findings for the conditions investigated (Figure 6).

Whereas the formation rates of gaseous and tarry components can be derived directly from experimental weight loss curves, this is not so for the tar deposition kinetics. For the deposition reaction the activation energy was therefore fixed at $60 \mathrm{~kJ} / \mathrm{mole}$. This comparatively low value is justifiable in view of the fact that a large number of independent deposition reactions proceed simultaneously. The frequency factor $K_{04}$ was initially estimated to be $2.7 \times 10^{4} \mathrm{~s}^{-1}$. This value gives a reasonable fit of the experimentally observed particle size dependence of the ultimate weight loss for German lignite. The overall tar deposition rate obtained in this way for the temperature range of interest, $600-800^{\circ} \mathrm{C}$, is in reasonable agreement with data published by Serio et al. (1983), who used two independent deposition reactions. Finally, the stoichiometric coefficient $\alpha$, governing the stoichiometry of the tar deposition reaction, was set at 0.8 , in approximate agreement with data of Arendt (1980).
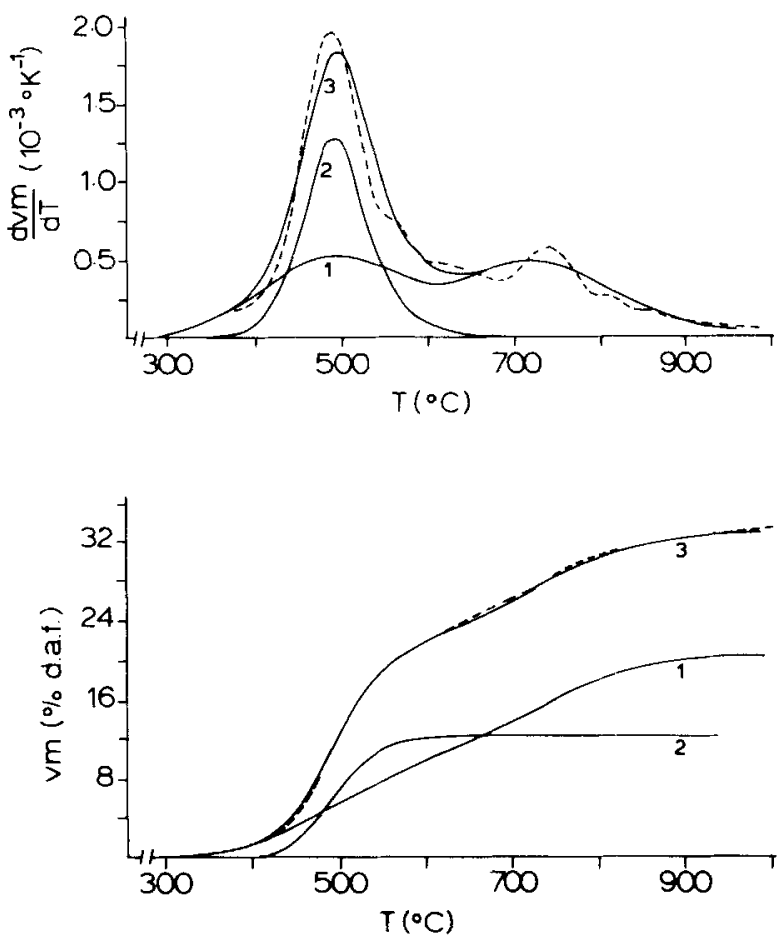

Figure 6. Devolatilization kinetics of Polish HVB coal

$$
\begin{aligned}
& m_{H}=50^{\circ} \mathrm{C} / \mathrm{min} ; P=0.1 \mathrm{MPa} \cdot \mathrm{N}_{2} ; d_{\mathrm{p}}=44-53 \mu \mathrm{m} \\
& \ldots-\text { Experimental } \\
& \text { - Simulation according to kinetic scheme in Fig. } 1 \text { (1, gas; } 2 \text {, tar; 3, total) }
\end{aligned}
$$

The analysis of the devolatilization behavior of large lumps of coal was performed in a specially constructed unit for weight loss recording, see Figure 5. The heart of this experimental set up is a Mettler PC 400 continuous balance, capable of handling sample weights up to $400 \mathrm{~g}$, with an accuracy of $0.01 \mathrm{~g}$. The experimental procedure is largely similar to that with a conventional TGA unit.

\section{MODEL PREDICTIONS}

The single-particle coal devolatilization model outlined above allows a quantitative assessment of both the intraparticle conditions and the macroscopically observable phenomena. The conversion-time behavior and the ultimate volatile yield especially are amenable to direct experimental observation. The modeling equations presented in the previous sections were solved numerically, see the appendix. The model was tested over a wide range of conditions. First, the predictions on the conversion time behavior and the ultimate coal weight loss will be discussed. Subsequently it will be shown how this behavior is influenced by the intraparticle conditions.

The conversion-time behavior of a devolatilizing coal particle is heavily influenced by the particle size and the heating rate. This is illustrated in Figure 7. For small particles mass and heat transfer resistances are almost absent. In this particle size regime the intraparticle tar concentration is governed by diffusional escape, at least at low heating rates (Figure 8). This concentration is too low for deposition reactions to occur. Consequently, the ultimate volatile yield is neither influenced by the ambient pressure, nor by the heating rate. The total devolatilization rate is kinetically controlled. With increasing heating rates the process is shifted toward higher temperature levels. Simultaneously, the maximum devolatilization rate increases. This behavior is, of course, generally found for decomposing solids (Jüntgen, 1970). 

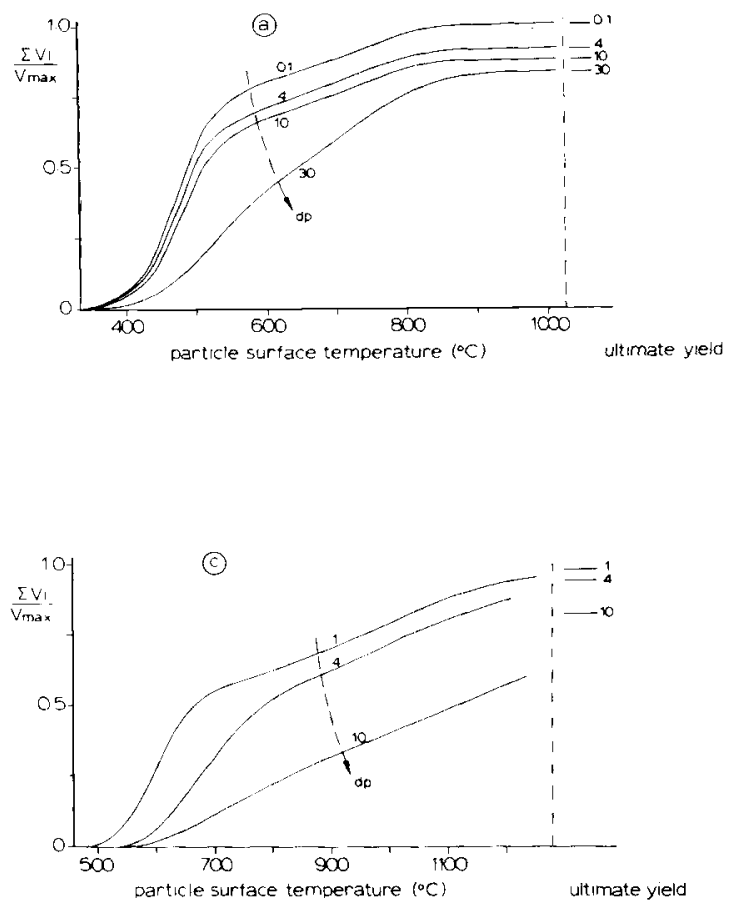
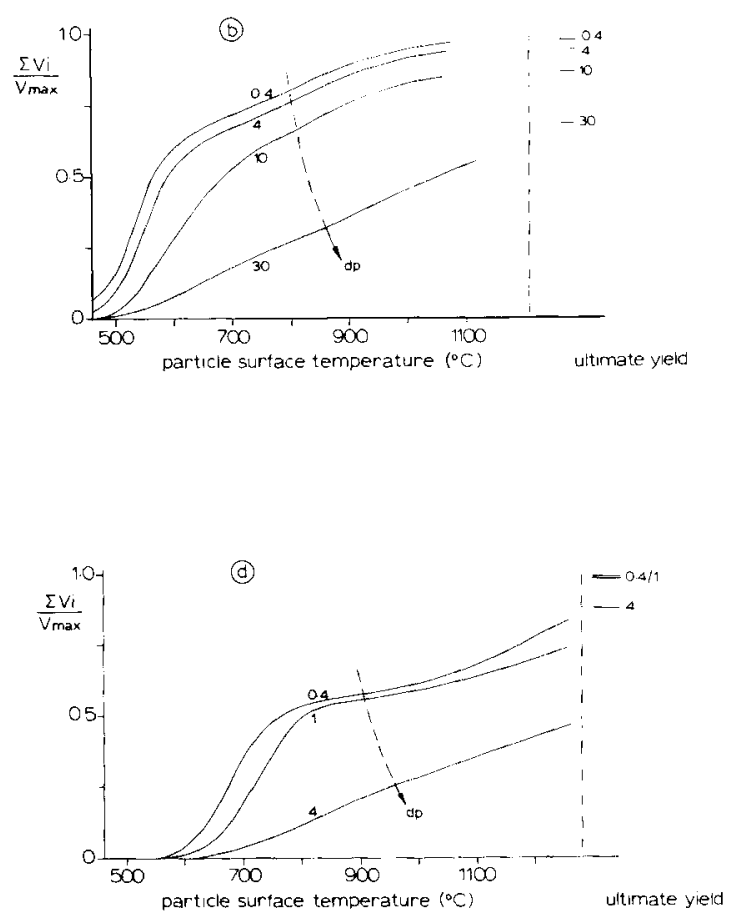

Figure 7. Devolatilization behavior; Polish HVB coal, model predictions.

$P=0.1 \mathrm{MPa}$

Variable: particle diameter in $\mathrm{mm}$ a. $m_{M}=0.5^{\circ} \mathrm{C} / \mathrm{s}$

b. $m_{h}=5^{\circ} \mathrm{C} / \mathrm{s}$ c. $m_{H}=50^{\circ} \mathrm{C} / \mathrm{s}$

d. $m_{H}=500^{\circ} \mathrm{C} / \mathrm{s}$
With increasing particle size both mass and heat transfer resistances develop. The steady state intraparticle heat transfer resistance is governed by the particle size and the heating rate, according to Eq. 22 (Carslaw and Jaeger, 1959).

$$
\Delta T=\frac{m_{H} \cdot R_{p}^{2}}{6 \cdot a}
$$

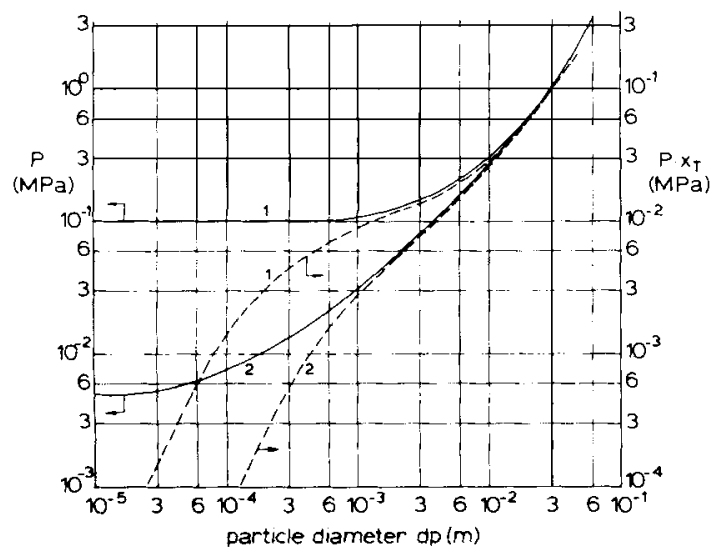

Figure 8. Maximum intraparticle tar and total pressure; Polish HVB coal, model predictions with $m_{H}=0.5^{\circ} \mathrm{C} / \mathrm{s}$.
As the thermal diffusivity $a$ changes in the course of devolatilization, the model predictions deviate slightly from Eq. 22; see Figure 9 for large particles. Along with the development of intraparticle temperature gradients, the escape of volatile components from the coal shifts from the diffusion controlled to the viscous flow controlled regime (Figure 8). The intraparticle pressure build-up and tar concentration increase rapidly. Whereas the full pressure equation was solved numerically in our model, an asymptotic analysis can be presented simply on the basis of the governing equations for tar and gas:

$$
\begin{aligned}
& \frac{1}{r^{2}} \frac{\partial}{\partial r}\left(r^{2} N_{g}\right)=\frac{1}{\rho_{o} M_{g}} \sum_{i} R_{g, i} \\
& \frac{1}{r^{2}} \frac{\partial}{\partial r}\left\langle r^{2} N_{t}\right)=\frac{1}{\rho_{o} M_{t}} \sum_{i} R_{t, i}
\end{aligned}
$$

For a homogeneously reacting coal particle Eqs. 23 and 24 can be integrated once, to obtain

$$
N_{t}=\frac{r}{3 \rho_{o} M_{t}} \sum_{i} R_{t, i}
$$

and

$$
N_{g}=\frac{r}{3 \rho_{o} M_{g}} \sum_{i} R_{g, i}
$$

On a molar basis the production rate of tarry volatiles is small compared to the production rate of gaseous species. Hence $x_{t}$ will remain close to zero and $\mathrm{Eq}$. 7, governing the pressure build-up, can be simplified to

$$
N_{t}+N_{g} / \sqrt{m}=-\frac{1}{\sqrt{m}} \cdot \frac{B o P}{\mu_{m} R T} \nabla P
$$


Table 3. Properties of Coal, Char, Gaseous and Takry Volatiles

\begin{tabular}{|c|c|c|c|}
\hline Parameter & Equation & Reference & Units \\
\hline$\lambda_{s}^{e}$ & $\begin{array}{l}T_{s}<773 \mathrm{~K} \lambda_{s}^{\varepsilon}=0.186 \\
T_{s}>773 \mathrm{~K} \lambda_{s}^{e}=0.186+3.61 \times 10^{-3}(T-773)\end{array}$ & $\begin{array}{l}\text { Badzioch (1964) } \\
\text { (linearized) }\end{array}$ & $\mathrm{J} / \mathrm{msK}$ \\
\hline$c_{p, s}$ & $c_{p, s}=870+2.55(T-273)$ & Melchior (1975) & $\mathrm{J} / \mathrm{kgK}$ \\
\hline$\theta_{p, t}$ & $\theta_{p, t}=\theta_{p, o}+\left(\theta_{p, \infty}-\theta_{p, o}\right)\left\{\frac{\rho_{o}-\rho_{t}}{\rho_{o}-\rho_{\infty}}\right\}$ & - & - \\
\hline$D_{g, t}$ & Eq. 12 & Reid et al. (1967) & $\mathrm{m}^{2} / \mathrm{s}$ \\
\hline$\Omega_{D}$ & $\begin{array}{l}\Omega_{D}=1.06 \cdot \frac{K T}{\epsilon_{g, t}}+0.193 \exp \left(-0.476 \frac{K T}{\epsilon_{g, t}}\right) \\
\epsilon_{g, t}=\left(\epsilon_{g} \epsilon_{t}\right)^{1 / 2}\end{array}$ & Reid et al. (1967) & - \\
\hline$\frac{\epsilon g}{K}$ & 136 & $\operatorname{Reid}(1967)$ & $\mathrm{K}^{-1}$ \\
\hline$\frac{\epsilon_{t}}{K}$ & 660 & Reidelbach (1979) & $K^{-1}$ \\
\hline$\mu_{m}$ & $\begin{array}{l}\mu_{m}=\frac{x_{g} \mu_{g}}{x_{g}+x_{t} \sqrt{m}}+\frac{x_{t} \mu_{t}}{x_{t}+\frac{x_{g}}{\sqrt{m}}} \\
\mu_{i}=\frac{\left(M_{i} T\right)^{1 / 2} \cdot 2 \cdot 10^{-26}}{\sigma_{i}^{2} \Omega_{V, i}}\end{array}$ & Reid (1967) & $\mathrm{Ns} / \mathrm{m}^{2}$ \\
\hline & $\Omega_{V, i}=1.165 \cdot\left(\frac{K T}{\epsilon_{i}}\right)^{-0.149}+0.525 \exp \left(-0.773 \frac{K T}{\epsilon_{i}}\right)$ & & \\
\hline$\sigma_{g, \ell}$ & $\begin{array}{l}\sigma_{g, t}=1 / 2\left(\sigma_{g}+\sigma_{t}\right) \\
\sigma_{g}=3.4 \times 10^{-10} \\
\sigma_{t}=10^{-9}\end{array}$ & $\begin{array}{l}\text { from critical temperature } \\
\text { and critical pressure data } \\
\text { of Reidelbach (1979) }\end{array}$ & \\
\hline$k_{o}$ & $0.4 \cdot \theta_{p}^{3}$ & Fig. 4 & \\
\hline Bo & $10^{-13} \cdot \frac{\theta_{p}^{3}}{\left(1-\theta_{p}\right)^{2}}$ & Fig. 3, Bliek (1984) & \\
\hline$M_{t}$ & 325 & Gavalas (1978) & \\
\hline$M_{g}$ & 20 & Gavalas (1978) & \\
\hline
\end{tabular}

When substituting Eqs. 25 and 26 in Eq. 27, and applying a single integration one obtains

$$
P_{r=0}^{2}-P_{r=R_{p}}^{2}=\frac{\mu_{m} R T}{3 \rho_{o} B o}\left\{\frac{\sum_{i} R_{g, i}}{M_{g}}+\frac{\sum_{i} R_{t, i} \sqrt{m}}{M_{t}}\right\} R_{p}^{2}
$$

For small particles the pressure build-up is limited and Eq. 28 can be reduced to

$$
P_{r=0}-P_{r=R_{p}}=\frac{\mu_{m} R T}{6 \rho_{o} B o}\left\{\frac{\sum_{i} R_{g, i}}{M_{g}}+\frac{\sqrt{m} \sum_{i} R_{t, i}}{M_{t}}\right\} \frac{R_{p}^{2}}{P_{r=R_{p}}}
$$

For large particles the pressure build-up is considerable and Eq. 28 can be simplified to

$$
P_{r=0}=\left\{\frac{\mu_{m} R T}{3 \rho_{o} B o}\left[\frac{\sum_{i} R_{g, i}}{M_{g}}+\frac{\sqrt{m} \sum_{i} R_{t, i}}{M_{t}}\right]\right\}^{0.5} R_{p}
$$

The limiting cases presented above are illustrated in Figures 10 and 11 , showing that for small particles the pressure build-up is proportional to $R_{p}^{2}$ and inversely proportional to the ambient pressure $P_{r=R_{p}}$, whereas for large particles the pressure build-up is proportional to $R_{p}$. The influence of the heating rate is manifested by the reaction rate terms $\Sigma_{i} R_{g, i}$ and $\Sigma_{i} R_{t, i}$.
Equations 22 and 29 show that with increasing particle size the volatiles formation rate tends to be heat transfer controlled, whereas the escape of volatiles is governed by the resistance to viscous flow. As a result of the former the instantaneous devolatilization rate is reduced, and as a result of the latter the deposition reactions act to reduce the total volatile yield. Both phenomena are reflected in Figure 7. For this intermediate particle size range the extent of tar deposition is governed by the mean tar concentration. When the mass transfer resistance is lowered by reducing the particle size or ambient pressure, the degree of tar deposition drops. A similar effect is observed when the intraparticle residence time is reduced by increasing the particle heating rate.

For very large particles or high heating rates, again different phenomena are observed. In these cases very steep temperature gradients develop and the devolatilization process adopts the form of a shrinking core reaction. The inner core of the coal particle starts releasing volatiles only after the particle surface has reached a temperature sufficiently high for deposition reactions to occur. The beginning of this behavior is noticeable for $30 \mathrm{~mm}$ coal particles heated at $0.5^{\circ} \mathrm{C} / \mathrm{s}$; see Figure 12 . For this case the extent of tar deposition is no longer governed by the mean tar concentration alone, but also by the thermal history of the tar molecules as they are transported through the coal. A rather unexpected consequence of this fact is that the yield of volatiles reaches a maximum as a function of the heating rate, see Figures 13 and 14. With increasing heating rate the intraparticle residence time is reduced. This is counteracted by the fact that the coal volatiles have to pass the outer region of the particle, which tends to be hotter when the heating rate increases. In contrast to the generally accepted opinion, the 


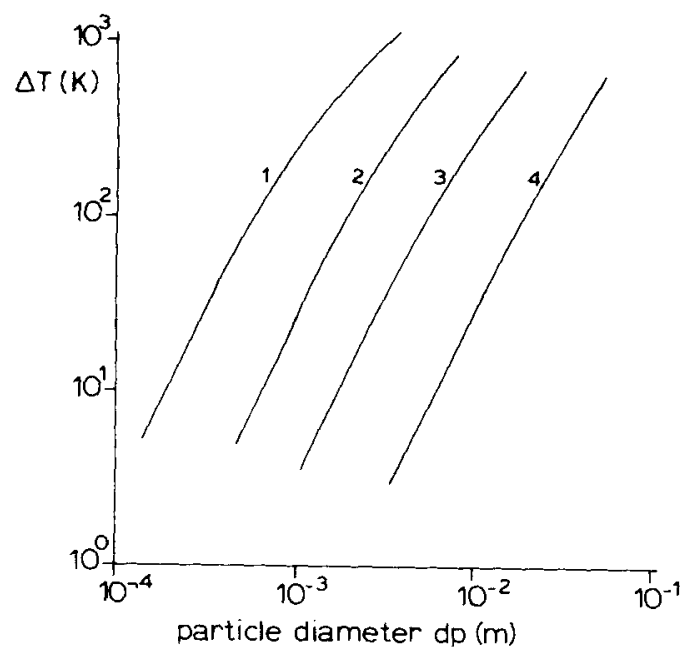

Figure 9. Maximum intraparticle temperature difference vs. particle size; Polish HVB coal, model predictions.
1. $m_{H}=500^{\circ} \mathrm{C} / \mathrm{s}$
2. $m_{H}=50^{\circ} \mathrm{C} / \mathrm{s}$
3. $m_{H}=5^{\circ} \mathrm{C} / \mathrm{s}$
4. $m_{\mathrm{H}}=0.5^{\circ} \mathrm{C} / \mathrm{s}$

effect of the heating rate is therefore not necessarily monotonic. The authors are not aware that this result has been shown before

\section{COMPARISON WITH EXPERIMENTAL OBSERVATIONS}

In this section the model predictions will be compared to experimental results, both from our own work and from various literature sources. It should be noted that the experimental results

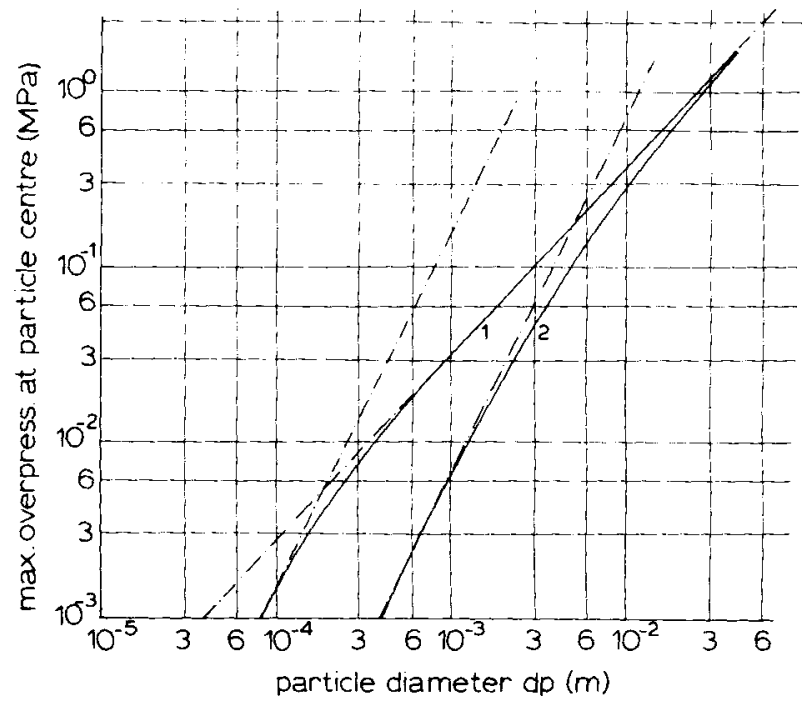

Figure 10. Maximum particle center overpressure; Polish HVB coal, model predictions.
$m_{H}-0.5^{\circ} \mathrm{C} / \mathrm{s}$
1. $P_{\mathrm{a}}=5 \mathrm{kPa}$
2. $P_{a}=0.1 \mathrm{MPa}$
-. - Limiting cases

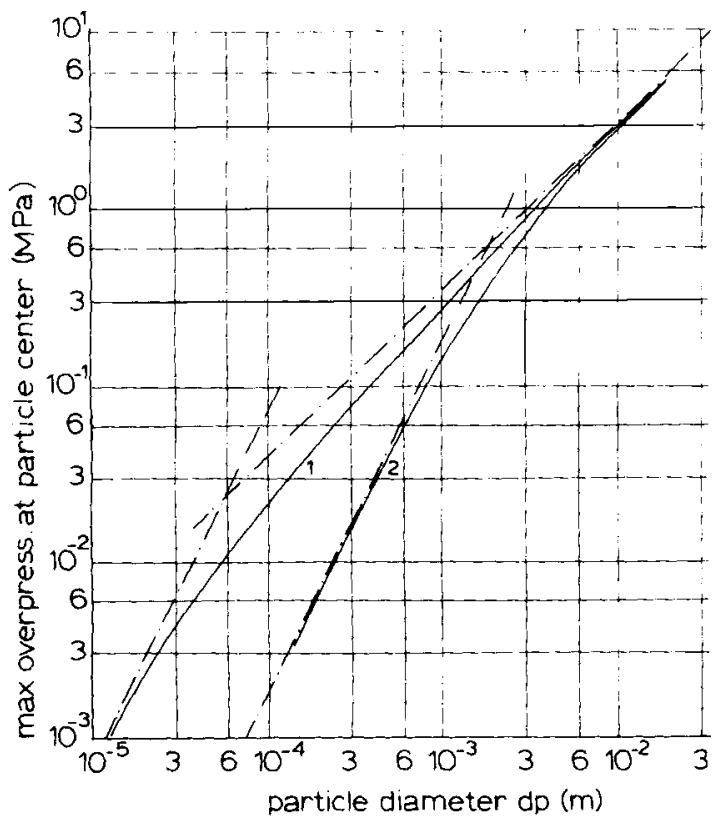

Figure 11. Maximum particle center overpressure; Polish HVB coal, model predictions.

$m_{H}=50^{\circ} \mathrm{C} / \mathrm{s}$.

1. $P_{a}=5 \mathrm{kPa}$

2. $P_{\mathrm{a}}=0.2 \mathrm{MPa}$

from our work merely reflect low heating rate conditions

The model needs several coal specific properties to perform its calculations. These include the kinetic constants for devolatilization and tar deposition, maximum tar and gas yields, heat and mass transfer properties, and the solid void fraction. With the exception of tar deposition kinetics, all parameters can be obtained by straightforward independent measurements.

A complete set of data is available for the two coals studied here. This is not always so for the coals studied by others. Hence, data for the Polish HVB coal (Tables 1, 2) will be assumed representative for the "Gasflammkohle Leopold" studied by Arendt (1980) and Pottgiesser (1980), as well as the Pittsburgh Seam bituminous coal studied by Anthony (1975). Similarly, the data obtained for German lignite will be assumed valid for the Montana lignite studied by Suuberg (1977). In all cases the ultimate volatile yield data were taken from literature, under conditions where deposition reactions can be assumed absent.

Ambient Pressure. The influence of the ambient pressure on the devolatilization of Leopold coal was systematically investigated by Pottgiesser (1980) and Arendt (1980). Our model predictions agree fairly well with both the high and low heating rate data reported by these authors, see Figure 15, though the value of $K_{04}$ had to be increased. Note that an increase of the ambient pressure from 0.01 to $0.3 \mathrm{MPa}$ results in a substantial reduction of the ultimate tar yield. Both the work of Anthony and Howard (1976) and our own experimental work show that the volatile yield of small particles continuously increases when the ambient pressure level is reduced to $\sim 10^{-5} \mathrm{MPa}$ (Figure 15 ). This cannot be explained by our model unless unrealistically high tar deposition rates are assumed. Such deposition rates would lead to a strong overprediction of the influence of particle size, see Figure 18. This discrepancy between the model and experimental results is not found for lignites. Possibly the structural changes of HVB coals during the mesophase formation are responsible for this behavior.

Particle Size. The influence of the coal particle size on the ultimate volatile yield is depicted in Figures 17 and 18. For low 

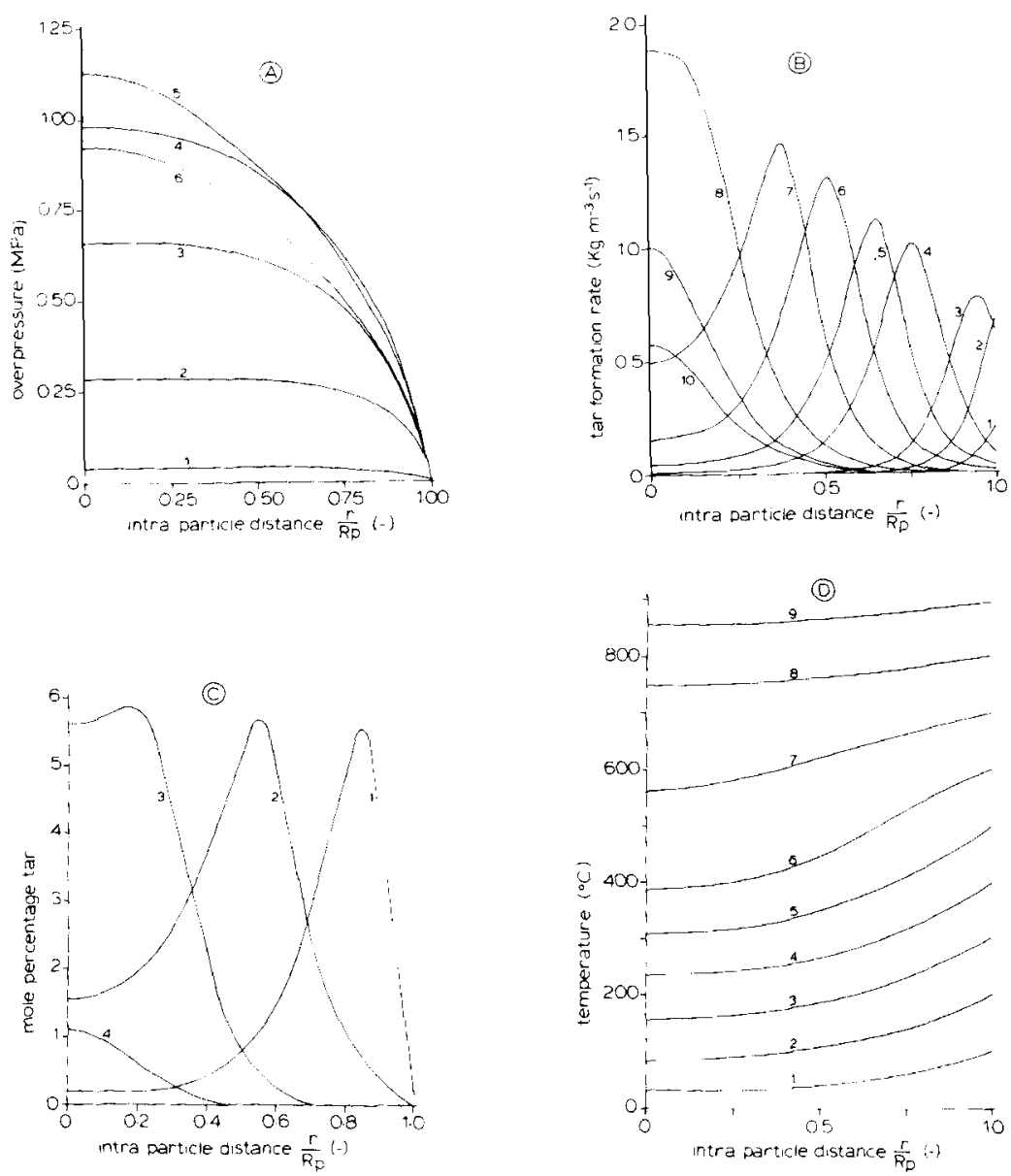

Figure 12. Intraparticle profiles of four factors at various time levels $t$. Polish HVB coal, model predictions.

$P_{.}=0.1 \mathrm{MPa} ; d_{p}=3 \cdot 10^{-2} \mathrm{~m} ; m_{H}=0.5^{\circ} \mathrm{C} / \mathrm{s} ; T_{o}=20^{\circ} \mathrm{C}$.

\begin{tabular}{|c|c|c|c|c|c|c|c|c|c|c|c|}
\hline \multirow[b]{3}{*}{ Fig. } & \multirow{3}{*}{$\begin{array}{c}\text { Faclor } \\
\text { evaluated }\end{array}$} & \multicolumn{10}{|c|}{ Time level, $t$, at which evaluation was made (s) } \\
\hline & & \multicolumn{10}{|c|}{ Curve No. } \\
\hline & & 1 & 2 & 3 & 4 & 5 & 6 & 7 & 8 & 9 & 10 \\
\hline A & Overpressure & 565 & 765 & 965 & 1,165 & 1,365 & 1,565 & - & - & - & - \\
\hline B & Tar formation rate & 802 & 880 & 965 & 1,094 & 1,165 & 1,208 & 1,278 & 1,315 & 1,365 & 1,377 \\
\hline c & Tar mole fraction & 1,076 & 1,217 & 1,319 & 1,377 & - & - & - & - & - & $\ldots$ \\
\hline D & Temperature & 165 & 365 & 565 & 765 & 965 & 1,165 & 1,365 & 1,565 & 1,765 & - \\
\hline
\end{tabular}

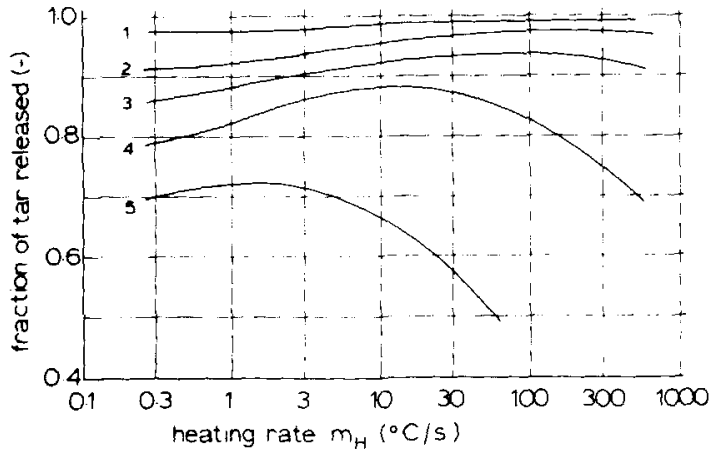

Figure 13. Fraction of tar ultimately released from the particle; Polish HVB coal, model predictions.

$P a=0.1 \mathrm{MPa}, K_{04}=2.7 \times 10^{4} \mathrm{~s}^{-1}$

1. $d_{p}=0.4 \mathrm{~mm}$

2. $d_{p}=1.0 \mathrm{~mm}$

3. $d_{\rho}=2.0 \mathrm{~mm}$

4. $d_{p}=4.0 \mathrm{~mm}$

5. $d_{p}=10.0 \mathrm{~mm}$ heating rates the experimental results of the German lignite presently studied are in excellent agreement with predicted values, for $K_{04}=2.7 \times 10^{4} \mathrm{~s}^{-1}$. With the Polish HVB coal a good fit is obtained when this frequency factor is somewhat lowered. Both Suuberg (1979) and Arendt (1980) have obtained experimental results concerning the influence of particle size at high heating rates. Unfortunately the particle size range studied is restricted and hardly any influence of deposition reactions can be observed, see Figure 19. As such this result is in agreement with the model predictions.

Heating Rate. The effect of the particle heating rate can be established on the basis of data from Anthony (1976) for Montana lignite, and Arendt (1980) for Leopold coal, see Figure 20. Anthony does not give any tar evolution data. Therefore the ultimate tar yield was taken from Suuberg (1980) reporting a yield of $6 \mathrm{wt} . \%$ for Montana lignite. Both the moderate increase in the tar yield observed by Arendt when going from 57 to $950^{\circ} \mathrm{C} / \mathrm{s}$, and the absence of any heating rate effect observed by Anthony, are satisfactorily covered by the model predictions. A more critical test of the present model cannot be made until a more extensive experimental program has been worked out. 

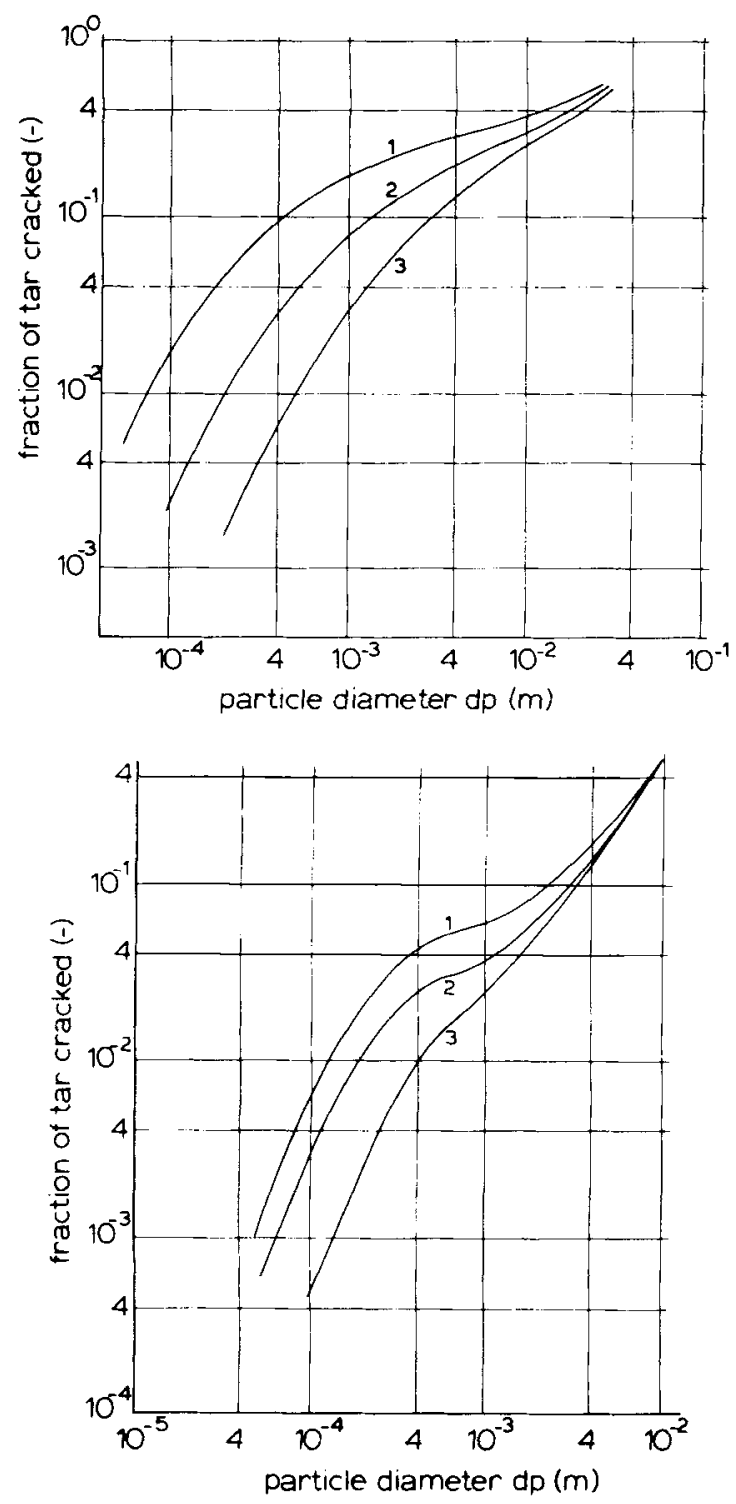

Figure 14. Fraction of tar cracked vs particle size; Polish HVB coal, model predictions for two heating rates.

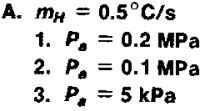

B. $m_{H}=50^{\circ} \mathrm{C} / \mathrm{s}$

1. $P_{a}=0.2 \mathrm{MPa}$

2. $P_{a}=0.1 \mathrm{MPa}$

3. $P_{a}=5 \mathrm{kPa}$

\section{DISCUSSION OF THE RESULTS}

The present model was formulated in an attempt to assess the role of intraparticle heat and mass transfer resistances upon the devolatilization of a single coal particle. It has been shown that the overall devolatilization rate can either be kinetically controlled or heat transfer controlled. On the other hand, the ultimate total volatile and tar yield are governed by mass transfer resistances. For small particles the mass transfer is governed by diffusion, whereas for larger particles the viscous flow controlled regime is rapidly entered.

A unidirectional relation exists between the ultimate volatile yield and the particle size and ambient pressure. These factors influence the mass transfer resistance and consequently they affect the degree of intraparticle tar deposition. The agreement between the model predictions and experimental results is fair on this point.

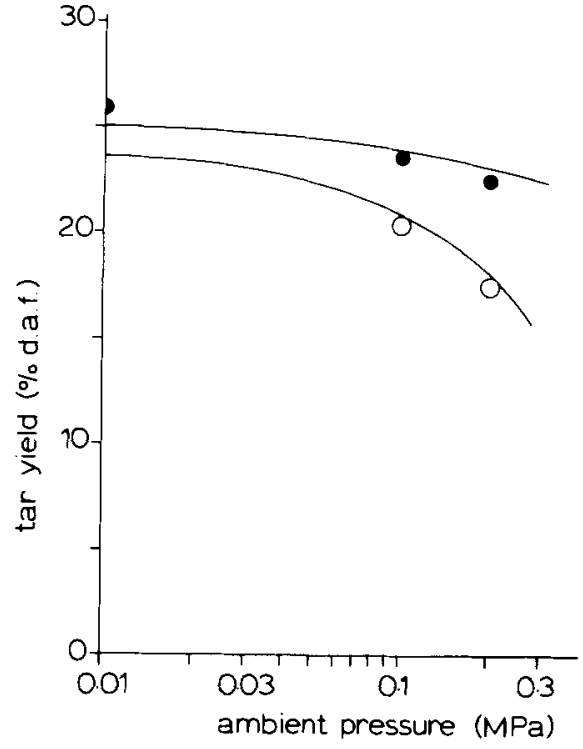

Figure 15. Tar yield vs. ambient pressure.

- Data of Arendt (1980) on Leopold coal $m_{H}=210^{\circ} \mathrm{C} / \mathrm{s} ; d_{p}=250 \mu \mathrm{m}$

O Data of Pottglesser (1980) on Leopold coal $m_{H}=0.05^{\circ} \mathrm{C} / \mathrm{s} ; d_{\rho}=900 \mu \mathrm{m}$

- Model predictions with $V_{T, \infty}=90 \mathrm{mg} / \mathrm{g} ; K_{04}=1.35 \times 10^{5} \mathrm{~s}^{-1}$

For bituminous coals the experimental results indicate that the volatile yield is influenced by the ambient pressure, even for very small particles. This result is at variance with the predictions of our model.

The particle heating rate influences the devolatilization process in a highly complicated manner. Obviously the devolatilization process is shifted to higher temperature levels when the heating rate is increased. This means that the volatiles are released at a higher temperature, where they are more liable to deposition reactions. On the other hand the instantaneous devolatilization rate increases, and the intraparticle residence time drops correspondingly. Because the activation energy for deposition is lower than the one for devolatilization, the net effect will be that the deposition reactions are suppressed. However, the heating rate also tends to influence the relative formation rates of gaseous and tarry

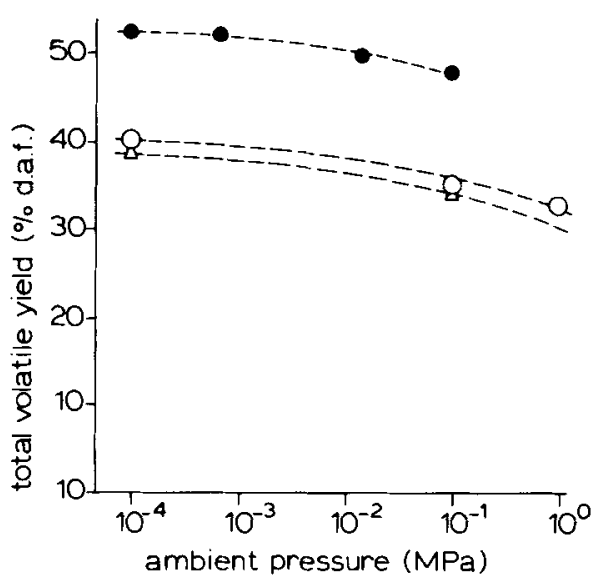

Figure 16. Total volatile yield vs. ambient pressure.

- Pittsburgh seam bituminous, Anthony (1976) $m_{H}=1,000^{\circ} \mathrm{C} / \mathrm{s} ; d_{p}=74 \mu \mathrm{m}$ O Pollsh HVB, this work $m_{H}=0.5^{\circ} \mathrm{C} / \mathrm{s} ; d_{p}=50 \mu \mathrm{m}$

$\triangle$ Polish HVB, this work $m_{H}=0.5^{\circ} \mathrm{C} / \mathrm{s} ; d_{p}=1,000 \mu \mathrm{m}$

-. Trend lines 


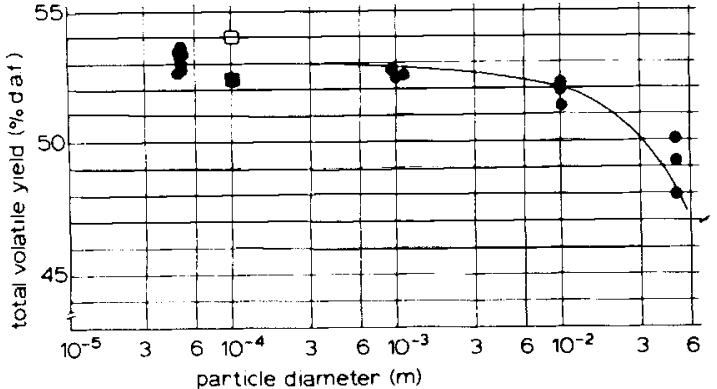

Figure 17. Total volatile yield vs. particle size; German lignite, this work.

$m_{H}=0.5^{\circ} \mathrm{C} / \mathrm{s}$

- Experimental $P_{a}=0.1 \mathrm{MPa}$

$\square$ Experimental $P_{A}=5 \mathrm{kPa}$

Experimental $P_{\mathrm{a}}=1.0 \mathrm{MPa}$

- Model predictions, $K_{04}=2.7 \times 10^{4} \mathrm{~s}^{-1}$

species, and thus the intraparticle tar mole fraction. Finally, the heating rate governs the intraparticle temperature profile and thus the thermal history of the tar molecules as they are transported through the coal. Under severe heat transfer controlled conditions, the volatiles released at the inner core of the particle tend to be deposited in the hotter outer layer. As a result of this phenomenon the ultimate volatile yield passes through a maximum as a function of the rate of heating. This illustrates that under heat transfer controlled conditions, the extent of tar deposition is both governed by the intraparticle residence time and by the existing intraparticle temperature gradients.

The experimental results on the influence of heating rate are confusing. Many investigators have reported volatile matter yields $10-40 \%$ above the standard volatile matter yield (see Anthony and Howard, 1976). Usually, high volatile yields are obtained with small particles at flash heating conditions. Basically, two explanations for this phenomenon have been offered. Kobayashi (1976) suggested that during coal devolatilization two competitive chemical routes can be followed, with distinctly different volatile yields. When the activation energy of these reaction paths is different, the devolatilization process may shift from one path to the other when the heating rate is changed. Arendt (1980) observed no influence of the heating rate over the range 57 to $950^{\circ} \mathrm{C} / \mathrm{s}$. A similar result

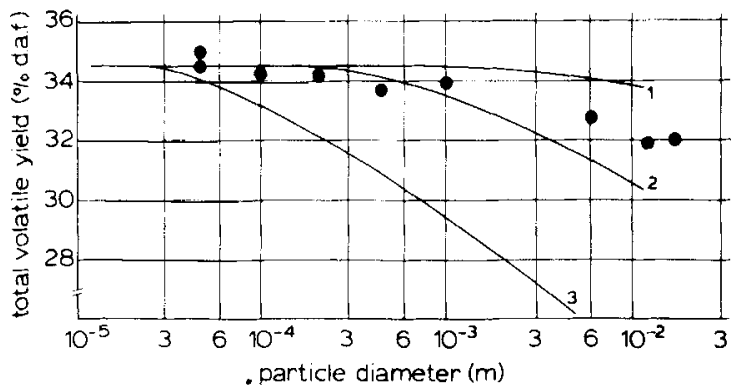

Figure 18. Total volatile yield vs. particle size; Polish HVB coal, this work.

$m_{H}=0.5^{\circ} \mathrm{C} / \mathrm{s} ; P_{a}=0.1 \mathrm{MPa}$

- Experimental

Model predictions

1. $K_{04}=2.7 \times 10^{3} \mathrm{~s}^{-1}$

2. $K_{04}=2.7 \times 10^{4} \mathrm{~s}^{-1}$

3. $K_{04}=2.7 \times 10^{5} \mathrm{~s}^{-1}$
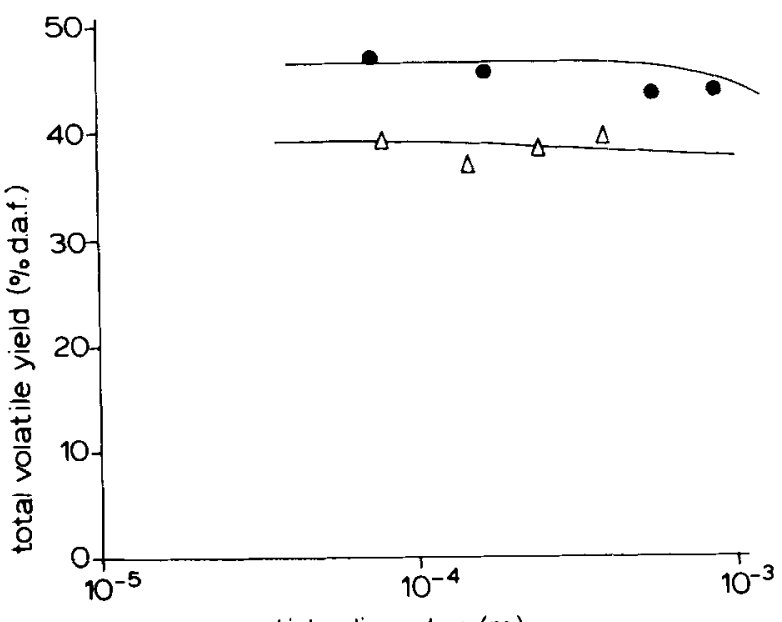

particle diameter $(m)$

Figure 19. Total volatile yield vs. particle size.

- Data of Suuberg (1979) on Pittsburgh Seam biluminous coal $m_{H}=1,000^{\circ} \mathrm{C} / \mathrm{s} ; P_{a}=$ $0.1 \mathrm{MPa}$

- Model predictions with $v_{l, \infty}=230 \mathrm{mg} / \mathrm{g} ; v_{g, \infty}=270 \mathrm{mg} / \mathrm{g} ; K_{04}=1.35 \times 10^{5}$ $\mathbf{s}^{-1}$

$\triangle$ Data of Arendl (1980) on Leopold coal $m_{M}=210^{\circ} \mathrm{C} / \mathrm{s} ; P_{a}=0.1 \mathrm{MPa}$

— Model predictions with $V_{T, \infty}=260 \mathrm{mg} / \mathrm{g} ; V_{g, \infty}=130 \mathrm{mg} / \mathrm{g} ; K_{04}=1.35 \times 10^{5}$ $s^{-1}$

was reported by Anthony and Howard (1976), who used $74 \mu \mathrm{m}$ coal particles and applied heating rates of 750 to $10,000^{\circ} \mathrm{C} / \mathrm{s}$. On the basis of their experimental findings Anthony and Howard suggested that low volatile yields, found at low heating rates, are a direct consequence of either inter- or intraparticle deposition reactions. The heating rate effect is thus ascribed to its influence on the intraparticle residence time of coal volatiles. For small particles this residence time is small and the heating rate would not have any influence. For large particles the application of high heating rates would result in a substantial reduction of the intraparticle residence time. Consequently less tar would be deposited and the ultimate volatile yield would increase.

Both views on the impact of heating rate have been discussed in a qualitative sense by Reidelbach (1979). On the basis of the model presented here, the explanation of Anthony et al. (1975) can be critically tested. As was shown, the volatile yield increases initially when higher heating rates are applied, as was suggested by

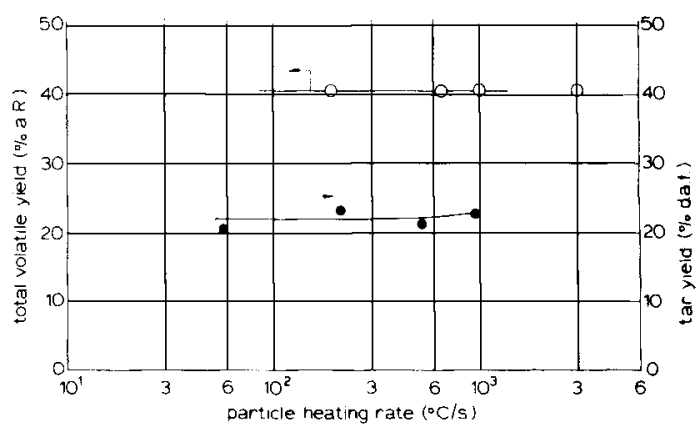

Figure 20. Total volatile yield vs. particle heating rate. $P_{\mathrm{a}}=0.1 \mathrm{MPa}$

O Data of Anthony (1976) on Montana lignite, $d_{\rho}=74 \mu \mathrm{m}$

- Model predictions, $V_{T, \infty}=60 \mathrm{mg} / \mathrm{g} ; V_{g, \infty}=346 \mathrm{mg} / \mathrm{g} ; K_{04}=1.35 \times 10^{5} \mathrm{~s}^{-1}$

- Data of Arendt (1980) on Leopold coal, $d_{p}=250 \mu \mathrm{m}$

- Model predictions, $V_{T, \infty}=260 \mathrm{mg} / \mathrm{g} ; V_{\mathrm{g}, \infty}=130 \mathrm{mg} / \mathrm{g} ; K_{04}=1.35 \times 10^{5} \mathrm{~s}^{-1}$ 
Anthony and Howard. However, this effect is small and it is reversed when a critical heating rate is exceeded. Hence, intra particle deposition reactions can not be held responsible for the observed increase in the volatile matter content during flash pyrolysis. Whereas it remains possible that interparticle deposition reactions are responsible, the crucible experiments of Kobayashi, discussed by Reidelbach, suggest otherwise. We therefore prefer the explanation offered by Kobayashi, who presumes that various competitive reaction sequences can be followed during devolatilization.

\section{ACKNOWLEDGMENT}

The authors gratefully acknowledge the financial support provided by Shell Coal International Ltd., London, and the Netherlands Energy Research Foundation, E.C.N. Part of this work was carried out within the framework of the Dutch National Coal Research Program.

\section{NOTATION}

$a=$ thermal diffusivity, $\mathrm{m}^{2} / \mathrm{s}$

$B o=$ viscous permeability, $\mathrm{m}^{2}$

$c_{p}=$ heat capacity, $\mathrm{J} / \mathrm{kg} \cdot \mathrm{K}$

$D_{k, i}=$ Knudsen diffusivity for $i$ th species, $\mathrm{m}^{2} / \mathrm{s}$

$D_{i, j}=$ binary gas phase diffusion coefficient, $\mathrm{m}^{2} / \mathrm{s}$

$d_{p}=$ particle size, $\mathrm{m}$

$d_{\text {po }}=$ pore size, $\mathrm{m}$

$E_{i}=$ activation energy for $i$ th reaction, $\mathrm{kJ} / \mathrm{mol}$

$E_{o}=$ mean activation energy, Eq. $2, \mathrm{~kJ} / \mathrm{mol}$

$f(E)=$ distribution function for $E$, Eq. 2

$K_{o, i}=$ frequency factor for $i$ th reaction, $1 / \mathrm{s}$

$k_{1}=$ permeability parameter for Knudsen diffusion, Eq. $8, \mathrm{~m}$

$k_{o}=$ permeability parameter for binary diffusion, Eq. 9

$m=M_{t} / M_{g}$

$m_{H}=$ surface heating rate, $\mathrm{K} / \mathrm{s}$

$M_{i}^{*}=$ molecular mass of $i$ th species, $\mathrm{kg} / \mathrm{Kmol}$

$M_{i}=$ molecular weight of $i$ th species, $\mathrm{N} / \mathrm{mol}$

$N_{i}=$ flux of $i$ th species, $\mathrm{mol} / \mathrm{m}^{2} \mathrm{~s}$

$n=$ number of components in mixture

$P \quad=$ pressure, $\mathrm{Pa}$

$R_{i}=$ rate of production of $i$ th species, $\mathrm{g} / \mathrm{g}$ coal

$R_{p}=$ particle radius, $m$

$r=$ radial distance from the particle centre, $\mathrm{m}$

$R=$ gas constant, $\mathrm{J} / \mathrm{mol} \cdot \mathrm{K}$

$S_{p}=$ specific particle internal surface area, $\mathrm{m}^{2} / \mathrm{m}^{3}$

$t=$ time, $\mathrm{s}$

$T=$ temperature, $\mathrm{K}$

$V_{i}=$ yield of $i$ th species, $\mathrm{g} / \mathrm{g}$ coal

$V_{i, \infty}=$ ultimate yield of $i$ th species, $\mathrm{g} / \mathrm{g}$ coal

$x_{j}=$ mole fraction of $j$ th species

\section{Greek Letters}

$\alpha=$ stoichiometric coefficient deposition reaction, Figure 1

$\beta=$ water saturation factor, Figure 3

$\epsilon / k=$ intermolecular attraction energy divided by Boltzmann constant, (K)

$\theta_{p} \quad=$ particle porosity

$\sigma=$ standard deviation in $E$, Eq. $2, \mathrm{~kJ} / \mathrm{mol}$

$\sigma_{i, j}=$ mean collision diameter of $i$ th and $j$ th species, $m$

$\rho=$ density, $\mathrm{kg} / \mathrm{m}^{3}$

$\lambda=$ thermal conductivity, $\mathrm{J} / \mathrm{sm} \cdot \mathrm{K}$

$\mu_{i}=$ viscosity of $i$ th species, $\mathrm{N} \cdot \mathrm{s} / \mathrm{m}^{2}$

$\Omega_{v}=$ collision integral for viscosity

$\Omega_{D}=$ collision integral for diffusion

\section{Subscripts}

$a \quad=$ value at bulk

$c \quad=$ value at particle center

$f$ = final value

$g \quad=$ gaseous components

$m=$ gas $/$ tar mixture

$=$ at $t=0$

$=$ solid components

= tarry components

$=$ at $t=\infty$

\section{Superscript}

$e \quad=$ effective

\section{APPENDIX: NUMERICAL TREATMENT}

Coal pyrolysis was modeled by three nonlinear partial differential equations: two mass conservation equations for the tar and gaseous volatiles respectively, and one heat balance equation. These equations were solved numerically by an implicit backward discretization scheme. By discretization the partial differential equations were reduced to three coupled sets of nonlinear algebraic equations. After linearization, a combination of iteration and the algebra of diagonal matrices produced the numerical results. As an example the heat balance will be taken. This balance reads

$$
\rho c_{p, s} \frac{\partial T}{\partial t}=\frac{l}{r^{2}} \frac{\partial}{\partial r}\left(r^{2} \lambda_{s}^{e} \frac{\partial T}{\partial r}\right)-\sum_{i=g, t} N_{i} M_{i} c_{p, i} \frac{\partial T}{\partial r}
$$

Both the time variable $t$ and the radial coordinate $r$ are evaluated at a number of discrete points, $N$ and $z$, respectively (Figure A1). Derivatives are replaced by truncated Taylor series:

$$
\begin{gathered}
\frac{\partial T}{\partial t} \simeq \frac{T_{z}^{N}-T_{z}^{N-1}}{\Delta t} \\
\frac{\partial T}{\partial r} \simeq \frac{T_{z+1}^{N}-T_{z-1}^{N}}{2 \Delta r}
\end{gathered}
$$

The heat balance thus reads in its discrete form

$$
\begin{aligned}
\rho_{z}^{N-1} c_{p, s}^{N-1} \frac{T_{z}^{N}-T_{z}^{N-1}}{\Delta t}=\frac{1}{r_{z}^{2}}\left\{r_{(z+1 / 2)}^{2} \lambda_{(z+1 / 2)}^{e} \frac{T_{z+1}^{N}-T_{z}^{N}}{(\Delta r)^{2}}\right. \\
\left.-r_{(z-1 / 2)}^{2} \lambda_{(z-1 / 2)}^{e} \frac{T_{z}^{N}-T_{z-1}^{N}}{(\Delta r)^{2}}\right\}-\sum_{i=g, t} N_{i} M_{i} c_{p, i}^{N-1} \frac{T_{z+1}^{N}-T_{z-1}^{N}}{2 \Delta r}
\end{aligned}
$$

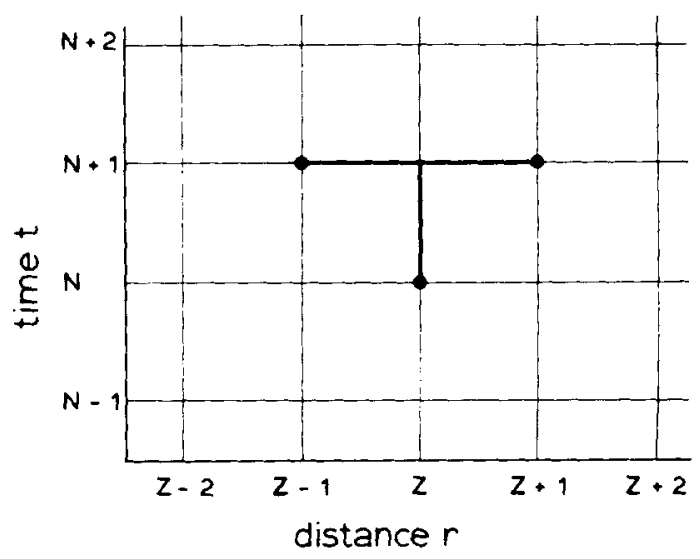

Figure A1. The time-distance scale for implicit backward discretization. 
$\left[\begin{array}{ccccc}B_{1} & C_{1} & 0 & \cdots & 0 \\ A_{2} & B_{2} & C_{2} & \cdots & 0 \\ 0 & A_{3} & & \vdots \\ \vdots & 0 & & \vdots \\ \vdots & \vdots & & \\ 0 & 0 & & A_{N} B_{N}\end{array}\right]\left[\begin{array}{c}T_{1} \\ T_{2} \\ \vdots \\ \vdots \\ T_{N}\end{array}\right]=\left[\begin{array}{c}D_{1} \\ D_{2} \\ \vdots \\ \vdots \\ D_{N}\end{array}\right]$

Figure A2. Tridiagonal matrix equations.

Note that the physical properties are evaluated at the previous time level to save computational time.

$$
\lambda_{\{z+1 / 2)}^{e} \simeq 1 / 2\left(\lambda_{(z+1)}^{e}+\lambda_{(z)}^{e}\right)
$$

The discretized equations are of the form

$$
A_{z} T_{z-1}+B_{z} T_{z}+C_{z} T_{z+1}=D_{z}, z=1(1) N
$$

As shown sparse coefficient matrix with only three nonzero diagonals. The matrix is easily solved by Gaussian elimination (von Rosenberg, 1969). Discretion of the mass balances for gas and tar proceeds along similar lines. The computational effort is greater because the abundance of nonlinear terms. All products of the kind $x \cdot p$ are linearized according to

$$
x p \simeq x \tilde{p}+\tilde{x} p-\tilde{x} \tilde{p}
$$

Both $\tilde{x}$ and $\tilde{p}$ are guessed values, improved by iteration. The resulting equations of the bitridiagonal kind (von Rosenberg, 1969) are again tackled by Gaussian elimination. The problem that heat and mass balances are coupled is overcome by iterating over the complete set of equations.

Two refinements have proved necessary. To cope with steep gradients just below the particle surface, the radial coordinate was transformed to obtain a fine grid at that point.

$$
\begin{gathered}
r=F(\psi) \\
\frac{d}{d r}=\frac{d \psi}{d r} \frac{d}{d \psi}=\left[F^{\prime}(\psi)\right]^{-1} \frac{d}{d \psi}
\end{gathered}
$$

A simple cubic equation was used for the transformation function

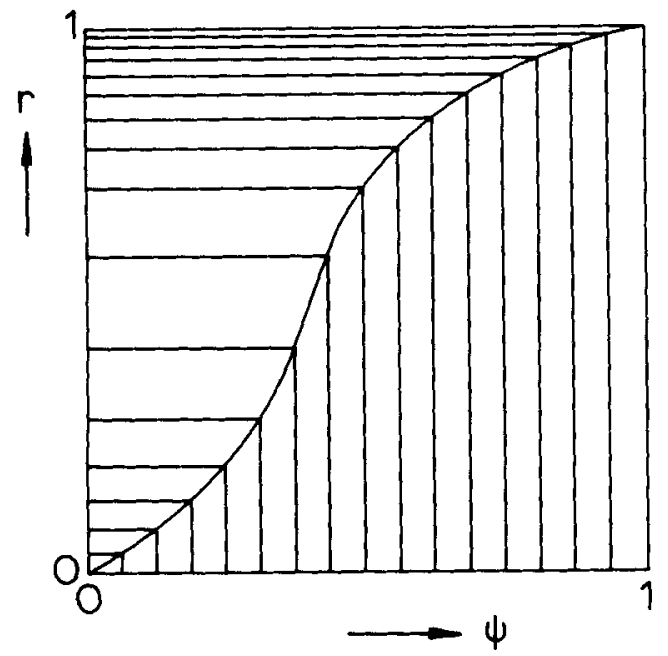

Figure A3. Coordinate transformation, using a cubic equation: $r=a \psi$ $+b \psi^{2}+c \psi^{3}$.
F, see Figure A3. During pyrolysis, abrupt changes in temperature, pressure, and mole fractions are possible. Numerically these features were dealt with by automatic adjustment of the time increment $\Delta t$, in order to keep these changes within reasonable limits. Under most circumstances the simple backward discretization scheme, together with linearization and iteration techniques, performed adequately. Usually 25 grid points were sufficient to solve a pyrolysis problem. However, the nonlinearity of the Dusty Gas transport equations gave convergence problems for high pressure $(>0.5 \mathrm{MPa})$ simulations.

\section{LITERATURE CITED}

Arendt, P., "Pyrolysis and Hydropyrolysis of Coals in the Pressure Range of 0.1 to 90 Atmosphere and Heating Rates of $10^{2}$ to $10^{3} \mathrm{~K} / \mathrm{s}$," Ph.D. Thesis, University Aachen, West Germany, (1980). (in German)

Arendt, P., and K. H. van Heek, "Comparative Investigations of Coal Pyrolysis under Inert Gas and $\mathrm{H}_{2}$ at Low and High Heating Rates and Pressures up to $10 \mathrm{MPa}$, Fuel, 60, 779 (1980).

Antal, M. J., et al., "Recent Progress in Kinetic Models for Coal Pyrolysis," 173rd Nat. Meet. A.C.S.; Div. Fuel Chem., 22, (1), 137 (1977).

Anthony, D. B., et al., "Rapid Devolatilization of Pulverized Coal," 15th Intl. Symp. on Combustion, The Combustion Institute, Pittsburgh, 1,303, (1975).

Anthony, D. B., and J. B. Howard, "Coal Devolatilization and Hydrogasification," AIChE J., 22, 625 (1976).

Aris, R., The Mathematical Theory of Diffusion and Reaction in Permeable Catalysts, Clarendon Press, Oxford (1975).

Arri, L. E., and N. R. Amundson, "An Analytical Study of Single Particle Char Gasification," AIChE J., 24, 72 (1978).

Attar, A., "Bubble Nucleation in Viscous Material Due to Gas Formation by a Chemical Reaction: Application to Coal Pyrolysis, AIChE J, 24, 106 (1978).

Badzioch, S., D. R. Gregory, and M. A. Field, "Investigation of the Temperature Variation of the Thermal Conductivity and Thermal Diffusivity of Coal," Fuel, 43, 267 (1964)

Badzioch, S., "Thermal Decomposition," Combustion of Pulverized Fuel, M. A. Field et al, B.C.U.R.A., England (1967).

Bhatia, S. K., and D. D. Perlmutter, "A Random Pore Model for Fluid Solid Reactions. II: Diffusion and Transport Effects," AlChE J., 27 (2), 247 (1981).

Bliek, A., "Mathematical Modeling of a Cocurrent Fixed Bed Coal Gasifier," Ph.D. Thesis, Twente University, The Netherlands (1984).

Campbell, J. H., "Pyrolysis of Subbituminous Coal in Relation to In-Situ Gasification," Fuel, 57, 217 (1978).

Carman, P. C., Flow of Gases through Porous Media, Academic Press, New York (1956).

Carslaw, H. S., and J. C. Jaeger, Conduction of Heat in Solids, 2nd ed., Oxford Univ. Press (1959).

Chang, P. W., K. Durai-Swamy, and E. W. Knell, "Kinetics of Coal Pyrolysis Reactions in a Flash Pyrolysis Process," Coal Process. Tech., 6, $20(1980)$.

Chen, L. H., and C. Y. Wen, "A Model for Coal Pyrolysis," Am. Chem. Soc., Div. Fuel Chem, Preprint 24 (3), 143 (1979)

Cheong, P. H. K., "A Modeling Study of Pyrolysis," Ph.D. Thesis, California Inst. Tech. (1977).

Chermin, H. A. G., and D. W. van Krevelen, "Chemical Structure and Properties of Coal. XVII: A Mathematical Model for Coal Pyrolysis," Fuel, 36, 85 (1957).

Dabbous, M. K., "The Permeability of Coal to Gas and Water," Soc. Petr. Eng. J., 14, 563 (1974).

Evans, R. B., III, G. M. Watson, and E. A. Mason, "Gaseous Diffusion in Porous Media at Uniform Pressure," J. Chem. Phys., 35, 2,076 (1961).

Gan, H., S. P. Nandi, and P. L. Walker, Jr., "The Nature of the Porosity in American Coals," Fuel, 51, 272 (1972).

Gavalas, G. R., and M. Oka, "Characterization of the Heavy Products of Coal Pyrolysis," Fuel, 57, 262 (1978).

Gavalas, G. R., and K. A. Wilks, "Intraparticle Mass Transfer in Coal Pyrolysis" AIChE J., 26 (2), 201 (1980).

Gray, J. A., P. J. Donatelli, and P. M. Yavorsky, "Hydrogasification Kinetics of Bituminous Coal and Coal Char," Am. Chem. Soc., Div. of Fuel Chem., Preprint 20 (4), 103 (1975). 
Hashimoto, K., and P. L. Silveston, "Gasification. II: Extension to Diffusion Control, AIChE J., 19 (2), 268 (1973).

Howard, J. B., and R. H. Essenhigh, "Pyrolysis of Coal Particles in Pulverized Fuel Flames," Ind. Eng. Chem. Proc. Des. Dev., 6, 74 (1967).

James, R. K., and A. F. Mills, "Analysis of Coal Particle Pyrolysis," Lett. Heat and Mass Trans., 3, 1 (1976).

Jüntgen, H., and K. H. van Heek, "Gas Release from Coal as a Function of the Rate of Heating," Fuel, 47, 103, (1968).

, "Course of Reaction under Nonisothermal Conditions," Fortschritte der Chemische Forschung, Springer Verlag, Berlin, 13,601, (1970). (in German)

Kalson, P. A., "Large Particle Coal Devolatilization and Tar Production from Lump Coal," Ph.D. Thesis, Univ. of Michigan, Univ. Microfilms, Ann Arbor MI (1981).

Khovanski, A. N., The Application of Continued Fractions and Their Generalization in Problems in Approximation Theory, Noordhof, 144 (1963).

Kobayashi, H., J. B. Howard, and A. F. Sarofim, "Coal Devolatilization at High Temperatures," 16th Intl. Symp. on Combustion, The Combustion Institute, 411 (1976).

Koch, V., H. Jüntgen, and W. Peters, "Nonisothermal Reaction Kinetics of Coal Pyrolysis. III: Course of the Reaction at High Heating Rates," Brennstoff Chem., 50, 369 (1969). (in German)

Lewellen, P. C., "Product Decomposition Effects in Coal Pyrolysis," M.Sc. Thesis, M.I.T. (1975).

Lien, C. L., "Permeability Characteristics of Coal Seams," Proc. 3rd Ann. Undergr. Coal Conv. Symp., Rept. Conf. 770,652, 454 (1977).

Luther, H. "Experiments to Determine Kinetic Quantities in the Isothermal Pyrolysis of Coal," Chem. Ing. Tech., $\mathbf{4 0}$ (7), 317 (1968). (in German)

Mahgoub, I., C. Prost, and J. A. Dodds, "Experimental Relative Permeability Curves Compared with a New Cutting and Joining Model of Porous Media with Distribution of Pore Sizes," Powder Technology, 31, 143 (1982).

Mason, E. A., A. P. Malinauskas, and R. B. Evans III, "Flow and Diffusion of Gases in Porous Media," J. Chem. Phys., 46, 3,199 (1967).

Mason, E. A., and A. P. Malinauskas, "Gas Transport in Porous Media: The Dusty Gas Model," Chem. Eng. Monograph 17, Elsevier, Amsterdam (1983).

Melchior, E., and H. Luther, "True Specific Heats of Cokes and Coals," Erdoel, Kohle, Erdgas, Petrochemie, 28, 379 (1975). (in German)

Mentser, M., H. J. O'Donnell, S. Ergun, "Rapid Thermal Decomposition of Bituminous Coals," Am. Chem. Soc., Div. Fuel Chem. Preprint, 14, (5), 94 (1970).

Millington, R. J., and J. P. Quirk, "Permeabilities of Porous Solids," Trans. Faraday Soc., 57, 1,200 (1961).

Nsakala, N. Y., R. H. Essenhigh, and P. L. Walker, Jr., "Studies on Coal Reactivity: Kinetics of Lignite Pyrolysis in Nitrogen at $800^{\circ} \mathrm{C}$," Comb. Sci. and Techn., 16, 153 (1977).

Oh, M., W. A. Peters, and J. B. Howard, "Modeling Mass Transport and Plasticity in Bituminous Coal Pyrolysis," Int. Conf. Coal Science, 483, Pittsburgh, (1983).

Otani, S., N. Wakao, and J. M. Smith, "Effect of Pressure Gradients on the Effectiveness of Porous Catalysts," AIChE J., 11, 446 (1965).

Peel, R. G., A. Benedek, and C. M. Crowe, "A Branched Pore Kinetic Model for Activated Carbon Adsorption," AIChE J, 27 (1), 26 (1981).

Peters, W., and H. Jüntgen, "Diffusion as a Controlling Factor of the Reactions of Coal and Coke," Brennstoff Chemie, 2, 46 (1964). (in German)

Pitt, G. J., "The Kinetics of the Evolution of Volatile Products from Coal," Fuel, 41, 267 (1962).

Pottgiesser, C., "Pyrolysis of Coals in the Pressure Range of 1 to $100 \mathrm{At}$ mosphere," Ph.D. Thesis, University of Aachen, West Germany (1980). (in German)

Rai, C., and Tran, D. Q., "Kinetic Models for Pyrolysis and Hydropyrolysis of Hanna Coal," Fuel, 58, 603 (1979).

Reid, R. C., J. M. Prausnitz, and T. K. Sherwood, The Properties of Liquids and Gases, McGraw-Hill, New York (1967).

Reidelbach, H., "Theoretical Studies on the Thermal Conversion of Single Coal Particles," Ph.D. Thesis, University of Stuttgart (1979). (in German)

Reidelbach, H., and R. Summerfield, "Kinetic Model for Coal Pyrolysis Optimization," 169th Nat. Meet. Am. Chem. Soc., Div., Fuel Chem. Preprint 20 (1), 161 (1975).

Reznik, A. A., "The Measurements of the Flow Properties of Coals for In Situ Gasification," DOE/COO-4639-4, UC 9oc, Final report (1978).

Roy, D. T., and K. P. Abraham, "An Analysis of the Pressure Build-Up Inside a Reacting Pellet During Gas Solid Reactions," Metall. Trans., 5,349 (1974).

Russel, W. B., D. A. Saville, and M. I. Greene, “A Model for Short Residence Time Hydropyrolysis of Single Coal Particles," AIChE J., 25, 65 (1979).

Schwandiner, D., "Carbonization of Coals at Heating Rates Higher than $10^{5} \mathrm{~K} / \mathrm{min}$," Ph.D. Thesis, Univ. Aachen, West Germany (1971). (in German)

Serio, M. A.; et al., "Secondary Reactions of Nascent Coal Pyrolysis Tars," Int. Conf. Coal. Science, Pittsburgh, 533 (1983).

Simons, G. A., and M. L. Finson, "The Structure of Coal Chars. 1: Pore Branching," Combust. Sci. and Tech., 19, 227 (1979).

Solomon, R. R., and M. B. Colket, "Coal Devolatilization," 17th Intl. Symp. on Combustion, The Combustion Institute, 131 (1978).

Solomon, P. R., "Relation between Coal Structure and Thermal Decomposition Products," Am. Chem. Soc., Div. Fuel Chem. Preprint, 24, 185 (1979).

Solomon, P. R., et al., "Correlation of Coal Volatile Yield with Oxygen and Aliphatic Hydrogen," Fuel, 60, 342 (1981).

Suuberg, E. M., W. A. Peters, and J. B. Howard, "Product Compositions in Rapid Hydropyrolysis of Coal," Fuel, 59, 405 (1980).

" "Product Composition and Kinetics of Lignite Pyrolysis," Am. Chem. Soc., Div. Fuel Chem., Preprint, 22 (1), 112 (1977).

Tien, R. H., and E. T. Turkdogan, "Incomplete Pore Diffusion Effect on Internal Burning of Carbon," Carbon, 8, 607 (1970).

Tsang, T. H. T., "Modeling Heat and Mass Transfer During Coal Block Gasification," Ph.D. Thesis, University of Texas, (1980).

Turkdogan, E. T., R. G. Olsson, and J. V. Vinters, "Pore Characteristics of Carbons," Carbon, 8, 545 (1970).

Tyler, R. J., "Flash Pyrolysis of Coals: Devolatilization of Bituminous Coals in a Small Fluidized Bed Reactor," Fuel, 59, 218 (1979).

Unger, P. E. and E. M. Suuberg, "Mass Transfer Effects in Vacuum and Atmospheric Pressure Pyrolysis of Coal," Int. Conf, on Coal Science, Pittsburgh, 475 (1983).

Vand, V., "A Theory of the Irreversible Electrical Resistance Changes of Metallic Films Evaporated in Vacuum," Proc. Phys. Soc. (London), A55, 222 (1943).

von Rosenberg, D. U., Methods for the Numerical Solution of Partial Differential Equations, Elsevier, New York, (1969).

Wakao, N., and J. M. Smith, "Diffusion and Reaction in Porous Catalyst," Ind. Eng. Fund., 3, 123 (1964).

Ward, C. E., and W. B. Russel, "On the Short Residence Time Hydropyrolysis of Single Coal Particles: The Effect of Unequal Diffusivities," AIChE J., 27, 859 (1981).

Wen, C. Y., and N. T. Wu, "An Analysis of Slow Reactions in a Porous Particle, AIChE J., 22 (6), 1,012 (1976).

Westmoreland, P. R., and R. C. Forrester, "Pyrolysis of Large Coals Blocks: Implications of Heat and Mass Transfer Effects for In-Situ Gasification," Am. Chem. Soc., Div. Fuel Chem., Preprint, 22, (1), 93 (1977).

Manuscript received Jan. 19, 1984; revision received Oct. 19 and accepted Oct. 29. 